\title{
Investigating the Links between UK House Prices and Share Prices with Copulas
}

\author{
Rakesh K. Bissoondeeal ${ }^{1}$ (D) Leonidas Tsiaras $^{1}$
}

Accepted: 9 February 2021/Published online: 23 August 2021

(C) The Author(s) 2021

\begin{abstract}
We investigate the nonlinear links between the housing and stock markets in the UK using copulas. Our empirical analysis is conducted at both the national and regional levels. We also examine how closely London house prices are linked to those in other parts of the UK. We find that (i) the dependence between the different markets exhibits significant time-variation, (ii) at the national level, the relationship between house prices and the stock market is characterised by left tail dependence, i.e., they are more likely to crash, rather than boom, together, (iii) although left tail dependence with the stock market is a prominent feature of some regions, it is by no means a universally shared characteristic, (iv) the dependence between property prices in London and other parts of the UK displays widespread regional variations.
\end{abstract}

Keywords Housing market $\cdot$ Stock market $\cdot$ Copulas $\cdot$ Regions

\section{Introduction}

The stock and housing markets are not only sources of investment assets for many investors, but are also two important pillars of an economy. Instabilities in these markets not only can lead to losses for investors but can also have a detrimental impact on domestic and global economies, as exemplified by the 2008 financial crisis. In this paper, we focus on gaining a deeper understanding of the nature of the relationship between the stock and housing markets in the UK. In particular, we seek to gain insights into the nonlinear dependence structures between the two markets. We know that instabilities in these markets can adversely affect the economy. Gaining a more in-

Rakesh K. Bissoondeeal

r.bissoondeeal@aston.ac.uk

Leonidas Tsiaras

1.tsiaras@aston.ac.uk

1 Aston University, Birmingham B4 7ET, UK 
depth knowledge of the relationship between the two markets can help us better understand their potential impact on the economy and support investment decisions during periods of turmoil. The impending Brexit, for example, can potentially have adverse effects on these markets. One of the consequences of Brexit will be the end of the free movement of labour and immigration from EU countries. In all likelihood, this will affect demand in the housing sector and thus potentially put downward pressure on house prices. Similar effects are also likely to be felt in the stock market. Less immigration implies less demand for goods and services and thus the share prices of many firms are likely to be affected. This effect is likely to be accentuated if the UK cannot reach a trade deal with the EU or make sufficient trade deals with other countries to offset the loss in trade with the EU. Several studies have shown that the two markets exhibit various forms of causal relationships (see, for example, Kapopoulos and Siokis 2005, Kakes and Van Den End 2004 and Lean and Smyth 2014). One implication of these findings is that if one of the markets is adversely affected, the other is likely to suffer similar consequences; or, if both are affected, the interrelationships between the two markets will deepen the initial adverse effects. It is therefore quite timely to be seeking to gain a deeper understanding of the relationship between the stock and housing markets in the UK.

The studies for the UK that are often cited in the literature are Sutton (2002) and Eichholtz and Hartzell (1996). Sutton (2002) studies the impact of total income, interest rates and stock prices on house prices for the UK, US, Canada, Australia, Netherlands and Ireland using a vector autoregressive model. For the UK, consistent with other countries, Sutton (2002) finds that there is a positive relationship between house prices and stock prices. Moreover, he finds that following a $10 \%$ increase in equity prices, house prices rise by $5 \%$ after three years. Eichholtz and Hartzell (1996) investigate the links between the two markets for the UK, US and Canada. Using property shares as a measure of real estate returns, they find that in all these countries the two markets exhibit a positive relationship according to both correlations and linear regressions. Bissoondeeal (2021), a recent study for the UK, adds to the earlier discussions by showing that the relationship between the housing market and the stock market is different in the long-run compared to the short-run. In the short-run, the study finds that the two markets are positively linked but in the long-run, they share a negative relationship.

The literature examining the relationship between the stock and housing markets has largely relied on linear techniques. However, some recent studies show that this relationship exhibits nonlinear characteristics. Aye et al. (2013) do not find evidence of either long-run or causal relationships between the two markets in South Africa using linear techniques. However, with the use of nonlinear techniques, in particular nonparametric cointegration, a long-run relationship is established. Moreover, they find evidence of bidirectional causality between the two markets using nonparametric Granger causality tests. For the US, Okunev et al. (2000) do not find any evidence of a long-run relationship between the two markets with linear methods. However, using the fractional cointegration approach, they find support for a long-run relationship. Moreover, using the linear approach they find evidence of a unidirectional causal relationship running from the real estate market to the stock market; but when nonlinear causality tests are employed, they find that the direction of causality is reversed. Similarly, Ding et al. (2014) do not find evidence of any linear causal relationships between the two markets in China. However, their results support the existence of causal relationships between real estate and the stock market in the upper and lower quantiles when quantile causality tests are employed. 
Given that the literature presents evidence of nonlinear structures in the relationship between the housing and stock markets, and it has predominantly used linear methods, this study will attempt to shed more light on the relationship between the two markets using nonlinear techniques. In particular, we will employ copulas (see, for example, Ning 2010) to understand in more depth the dependence structure between the housing and stock markets in the UK. The copula approach is fairly novel; it is useful for studying nonlinear dependence between variables. According to Sklar's (1959) theorem, the joint distribution of, say, two variables can be decomposed into their respective marginal distributions and a copula function. The latter characterises the dependence structure of the two variables under consideration. Copulas are particularly useful for studying tail dependence. In the context of housing and stock markets, copulas can be used to study whether the two markets are more likely to crash or boom together. Understanding the dependence structure between these variables is vital to, for example, risk managers. A popular measure of dependence is the correlation coefficient, which measures the strength and direction of a linear relationship between two variables. This is a useful measure if the dependence structure between two random variables is linear, but if the dependence structure is nonlinear, an alternative approach, such as copulas, is required. Copulas allow a great deal of flexibility in specifying the joint distribution of variables and are suitable for capturing nonlinear associations. A more detailed presentation of copulas follows in the next section.

Knight et al. (2005) employ copula functions to study the links between the real estate and equity markets in the UK. They use a constant copula to examine the dependence structure between real estate indices (constructed from a portfolio of real estate stocks) and equity prices in the UK (represented by the FTSE All Share Index) and the global market (proxied by the Morgan Stanley World Equity Series). Using data from the 1986-2004 period, they report stronger left tail dependence for the case of the UK but symmetric dependence for the case of the global indices. ${ }^{1}$ Our study differentiates itself from Knight et al. (2005) in many ways. First, we use the UK house price index in contrast to a portfolio of real estate securities, and hence our findings are more applicable to policymakers or financial institutions that have direct exposure to the housing market. Second, we consider both constant and time-varying copula models. Our findings indicate that time-varying dependence is indeed an important feature of the housing-stock market relationship. Third, our paper examines the relationship between the stock market and house prices at both the national and regional levels.

There is a growing literature that shows that there are important differences in the characteristics of each of the individual regional housing markets. For example, Green (2002), using linear models, studies the links between the stock and housing markets for different regions in California, US. He finds evidence of Granger causality running from share prices to house prices, but with a significant regional disparity. In particular, he finds that share prices only Granger cause house prices in regions with high-income households. He discusses that high-income households are more likely to hold relatively large amounts of stocks. In a similar vein, Kapopoulos and Siokis (2005) find evidence of causality running from share prices to house prices in the capital, Athens,

\footnotetext{
${ }^{1}$ Knight et al. (2005) also experiment with the Investment Property Databank (IPD) index but due to this series being subject to smoothing they fail to obtain any meaningful results. For this reason, they focus on real estate securities and their relationship with the overall equity market instead.
} 
but not in other urban areas of Greece. In the UK, house prices show considerable variations across different regions. House prices in the South East and the London commuter belt tend to be significantly higher than those in other parts of the UK. We will, therefore, also seek to establish if there are regional disparities, and the nature of those disparities, in the relationship between the housing and stock markets using the copula approach.

Within the literature on the regional analysis of the housing market, there is a strand looking at the dominant roles of major cities. Holly et al. (2011) and MacDonald and Taylor (1993), for example, show that London plays a leading role in terms of influencing house prices in other regions. Along these lines, given that London property prices tend to be the highest in the UK and are affected not just by domestic but also global economic conditions, we will investigate their linkages with other regions using the novel framework of copula functions. There are some antecedents to this work, albeit they are based on US data. Zimmer (2012) examines four US state-level house price indices (California, Arizona, Nevada, Florida) using constant copulas and finds that models that can accommodate tail dependence provide a superior fit to the data compared to the linear dependence case implied by the Normal copula. Ho et al. (2016) replicate the study of Zimmer (2012) using an updated dataset and a non-parametric copula specification and find that the key results remain intact. Zimmer (2015) investigates the relationship between monthly house prices (measured using Case-Shiller indices) in four US cities (New York, Miami, Los Angeles, Phoenix). Unlike previous studies that assume that dependence is constant, Zimmer (2015) demonstrates that the degree of covariation between house prices varies significantly across time. Specifically, a time-varying Student's $t$ copula, which allows for symmetric tail dependence is employed but no other copula specification is considered in the study. We build on these earlier studies by employing a wider copula function collection. In particular, in contrast to Zimmer (2012) and Ho et al. (2016), we relax the assumption of constant dependence as we also include time-varying specifications in the analysis. Clearly, as our empirical results show, allowing for time-varying dependence is very important. Moreover, while the time-varying copula model of Zimmer (2015) imposes symmetric tail dependence, in our specifications dependence is allowed to be both time-varying as well as asymmetric. Indeed, we find that in many cases a failure to accommodate both of these features can lead to an underestimation or an overestimation of crash risk that can be quantitatively large and qualitatively important.

Our study provides some novel insights into the dependence structure between the housing and stock markets in the UK. Previous studies based on linear models have shown the existence of a positive association between the two markets (Sutton 2002; Eichholtz and Hartzell 1996); our findings suggest that this positive association is stronger when two markets are experiencing a substantial downturn. Our findings are in line with Knight et al. (2005) that report stronger left tail dependence between UK real estate securities and the aggregate stock market in their constant copula study. Further to this, our paper shows that the dependence between the stock and national UK housing market is both asymmetric and time-varying and that using a constant copula can significantly underestimate tail risk.

Our regional analysis also provides important insights. Similar to Green (2002) and Kapopoulos and Siokis (2005), we report that the relationship between house prices and the stock market exhibits significant regional variation. Notably, in our study, we find that the stronger left tail dependence observed at the national level is shared by 
only five of the $13 \mathrm{UK}$ regions. The dependence structure of property prices of other regions with London is also not uniform. When dependence is assumed to be constant, our results resemble those of Zimmer (2012) and Ho et al. (2016) for the US case. Specifically, we find that, for most cases, dependence in both tails is stronger than that implied by the Normal copula. However, similar to Zimmer (2015), we find that time-variation in the dependence structure appears to be a salient feature for most regions (11 out of 12). In terms of tail dependence characteristics, we find substantial variation in our data.

The remainder of the paper is organised as follows. The next section (Copula Functions) provides a brief description of copula functions. The third section (Data) presents the dataset. Our empirical results are presented and discussed in the fourth section (Results and Analysis). The final section (Concluding Remarks) provides concluding remarks.

\section{Copula Functions}

To examine the dependence structure between the stock and housing markets, we attempt to model their conditional joint distribution using copula theory. Copula functions are multivariate cumulative distribution functions with marginals that follow a uniform distribution from 0 to 1 . Using Sklar's (1959) theorem, the joint probability density can be decomposed into a product of the marginal densities and the density of the copula, so that one can model the univariate dynamics separately and then apply a copula function to construct a valid joint distribution. This enables us to empirically investigate whether the relationship between the two markets exhibits nonlinear characteristics, including different levels of dependence in the right and left tails of the distribution.

We apply the conditional copula model introduced by Patton (2006) to capture the dynamic behaviour of the marginal distributions to gain further insights into the dependence structure between the housing and stock markets. For a bivariate case, let $F_{t}(x)$ and $G_{t}(y)$ denote the conditional cumulative distributions of two variables, and $K_{t}(x, y)$ denote their joint distribution function. $^{2}$ The corresponding conditional probability densities are denoted as $f_{t}(x), g_{t}(y)$ and $k_{t}(x, y)$. The conditional copula decomposition implies the following representation for the conditional joint distribution and corresponding density function,

$$
\begin{gathered}
K_{t}(x, y)=C_{t}\left(F_{t}(x), G_{t}(y)\right) \\
k_{t}(x, y)=c_{t}\left(F_{t}(x), G_{t}(y)\right) \cdot f_{t}(x) \cdot g_{t}(y),
\end{gathered}
$$

\footnotetext{
${ }^{2}$ Following Patton (2006), the term "conditional distribution" means that these distributions are "conditioned" on some common information set that contains the variables needed to estimate the models. In our application, the (time t) information set includes all past observations of the house and share price series, as well as past interest rate and real income data (which enter as explanatory variables in the conditional mean equations). Using this conditioning set, we can estimate the conditional mean and conditional variance equations, and hence the (time t) conditional distribution of each margin. Similarly, the same information set can be used to estimate the conditional copula model, presented in equations (3)-(5).
} 
where $C_{t}$ and $c_{t}$ are, respectively, the conditional cumulative distribution and probability density functions ${ }^{3}$ of the copula.

There are different types of copulas, each representing a different dependence structure. For example, symmetric copulas, such as Gaussian or Student's $t$, exhibit equal dependence in the tails. On the other hand, the asymmetric copulas display greater dependence in one of the tails. For instance, the Clayton copula exhibits greater dependence in the left tail than in the right tail. The Gumbel copula, contrarily, displays greater dependence in the right tail as compared to the left tail.

Following the standard practice in the literature (Creal et al. 2013; Patton 2013), we will first estimate copula models that assume that the dependence structure between the two markets is constant over time and subsequently consider specifications that allow the dependence structure to be time-varying. ${ }^{4}$ In the latter case, we allow the degree of dependence to evolve over time using the Generalized Autoregressive Score (GAS) copula dynamics introduced in Creal et al. (2013) and recommended by Patton (2013) among others. In this class of models, the parameter $\theta_{t}$ of a given copula is evolving according to a constant, the lagged dependence parameter, and a 'forcing variable' related to the standardized score $s_{t}^{*}$ of the copula's log-likelihood. Denoting $m($.) as the function that ensures that the estimated copula parameter lies within the appropriate boundaries, the time-varying GAS $(1,1)$ copula model is given by:

$$
\begin{gathered}
\theta_{t}=m\left(f_{t}^{*}\right) \\
f_{t+1}^{*}=\omega+\beta f_{t}^{*}+\alpha I_{t}^{*-0.5} s_{t}^{*} \\
I_{t}^{*} \equiv E_{t-1}\left[s_{t}^{*} s_{t}^{* \prime}\right]
\end{gathered}
$$

where $\mathrm{E}[\cdot]$ is the expectation operator, $s_{t}^{*} \equiv \frac{\partial}{\partial \theta_{t}} \log c_{t}\left(u_{t}, v_{t}, \theta_{t}\right), u_{t}=F_{t}(x)$ and $v_{t}=G_{t}(y)$.

\section{Models for Marginals}

Following the literature, we adopt a fully parametric approach in estimating the marginals. More specifically, following studies such as Bollerslev (1987), Patton (2006) and Ning (2010), we use the generalised autoregressive conditional heteroscedasticity $(\mathrm{GARCH})$ model to estimate the univariate distributions. In particular, to model the quarterly dynamics between the stock and housing markets, we use GARCH models with the following general specification:

\footnotetext{
${ }^{3}$ The subscript $t$ indicates that the marginal distributions, as well as their dependence are time-varying. For the special case of static marginal distributions and/or copula, the corresponding subscripts can be dropped.

${ }^{4}$ Comparisons between the various copula models are based on the Schwarz Information Criterion (SIC), i.e., our preferred model has the lowest SIC statistic.
} 


$$
\begin{gathered}
r_{t}=\mu+\sum_{n=1}^{4} \beta_{n}^{S P} r_{t-n}^{S P}+\sum_{n=1}^{4} \beta_{n}^{H P} r_{t-n}^{H P}+\sum_{n=1}^{4} \beta_{n}^{G D P} r_{t-n}^{G D P}+\sum_{n=1}^{4} \beta_{n}^{I} r_{t-n}^{I}+\sum_{n=1}^{4} \beta_{n}^{L} r_{t-n}^{L}+e_{t} \\
e_{t}=\sqrt{h_{t}} z_{t}, z_{t} \sim \text { i.i.d.DIS } \\
h_{t}=\widetilde{\omega}+\widetilde{\alpha} e_{t-1}^{2}+I D_{t-1} \widetilde{\alpha * e_{t-1}^{2}}+\widetilde{\beta} h_{t-1}
\end{gathered}
$$

where $r_{t}$ denotes the logarithmic change in either real house or share prices, $r_{t}^{S P}$ denotes the logarithmic change in real share prices, $r_{t}^{H P}$ denotes the logarithmic change in real house prices, $r_{t}^{G D P}$ denotes the logarithmic change in real income, $r_{t}^{I}$ denotes the change in interest rates and $r_{t}^{L}$ when the investigation is conducted for London or the national level. The choice of variables is guided by previous studies such as Sutton (2002) and we will estimate parsimonious versions of Eq. 6 based on the statistical significance of variables. For the conditional variance equation, we consider both the symmetric $\operatorname{GARCH}(1,1)$ as well as the asymmetric GJR-GARCH(1,1) specification of Glosten et al. (1993). The latter model can capture asymmetric volatility responses to past squared returns through the additional $\widetilde{\alpha_{*}}$ parameter and the indicator function $I D_{t}$ that takes the value of one if $e_{t}<0$ and zero otherwise. ${ }^{6}$ As with all GARCH models, the standardised residuals $z_{t}$ follow a distribution that has zero mean and unit variance. In our paper, this distribution, denoted as DIS, is either the standard Normal, the standardised Student's $t$, or the skewed $t$ distribution of Hansen (1994). So, in total, we estimate six alternative GARCH models (GARCH( 1,1$)$ or GJR-GARCH $(1,1)$ with either Normal, Student's $t$, or skewed $t$ distribution for the standardised residuals) for each series. Model selection is based on the Schwarz Information Criterion (SIC), where the preferred model is the one attaining the lowest SIC value.

Before proceeding with the implementation of a conditional copula model for the joint distribution, it is essential that we test whether the standardised residuals from each marginal model are consistent with a series of probability integral transforms that are i.i.d. uniform from 0 to 1 . If the marginal distributions are not correctly specified, the copula density, and indeed the entire joint distribution, will become invalid. Towards this end, we perform several misspecification tests on the models for the marginals. In particular, we use (i) the test of Diebold et al. (1998) to test for zero autocorrelation in the first four moments of the standardised residuals, (ii) the Kolmogorov-Smirnov test to examine the adequacy of the uniformity assumption; (iii) the likelihood ratio test of Berkowitz (2001) to test jointly for uniformity and independence; and (iv) 'Hit' regression tests to examine whether the conditional distributions are well specified, not only for the entire distribution but also for different segments of the density. In particular, we use the 'Hit' regression tests of Patton (2006) to test for any misspecifications in the left, centre, and right tails of the distribution.

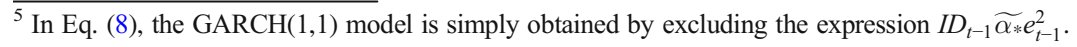




\section{Data}

We use quarterly data from 1973Q4 to 2016Q3. The starting date is determined by the house price data, which is obtained from the website of Nationwide. ${ }^{7}$ In addition to the national house prices, the prices of the following regions, which make up the UK are also considered: North (N), Yorkshire and Humberside (YH), North West (NW), East Midlands (EM), West Midlands (WM), East Anglia (EA), Outer South East (OSE), Outer Metropolitan (OM), London (L), South West (SW), Scotland (SC), Northern Ireland (NI) and Wales (WA). Data on share prices, total income, interest rates and the overall price level are obtained from Datastream. The FTSE All Share price index (SP) represents the stock market activity in the UK; Gross Domestic Product (GDP) is used as a measure of total income and the three-month Treasury Bill rate (I) is used as the representative interest rate. The GDP deflator represents the overall price level and is used to convert nominal variables into real variables. Apart from the interest rate, all variables are in seasonally adjusted form.

\section{Results and Analysis}

\section{Estimation of Marginals}

Estimation of marginals is based on Eqs. 6, 7 and 8. Parsimonious versions of Eq. 6 for share prices, UK national house prices, and all the different regional house prices are obtained by examining the statistical significance of the independent variables. As noted earlier, we estimate six versions of the GARCH model and use SIC values to choose the best specification. ${ }^{8}$ The SIC values for all the estimated GARCH models are displayed in Table 1, where the best models are highlighted. For share prices, EA and $\mathrm{SW}$, a GARCH with Student's $t$-distribution provides the best fit to the data. For NW, WM and SC, our empirical results indicate that the GJR-GARCH model with a Normal disribution is the more appropriate specification. In particular, the positive values of the estimated parameter $\widetilde{\alpha_{*}}$ for these regions (displayed in Table 2) imply that their volatility processes exhibit asymmetric responses to past price innovations, with large price drops leading to stronger volatility increases compared to large price appreciations. For the other dependent variables, a standard GARCH with a Normal distribution is the preferred specification. The explanatory variables appearing in the mean equations were also considered for the corresponding variance equations but, since none of them was significant, they have been dropped from the final models. ${ }^{9}$ The resulting specifications for each of the dependent variables are given in Table 2; the numbers in parentheses are $t$-statistics.

\footnotetext{
$\overline{{ }^{6} \mathrm{http}: / / w w w . n a t i o n w i d e . c o . u k / a b o u t / h o u s e-p r i c e-i n d e x / d o w n l o a d-d a t a \# x t a b: r e g i o n a l-q u a r t e r l y-s e r i e s-a l l-~}$ properties-data-available-from-1973-onwards

${ }^{7}$ We have also investigated versions of the GARCH and GARCH-GJR models that do not include the persistence parameter $\widetilde{\beta}$ in Eq. (8). These are essentially the "ARCH" versions of these models. Our results indicate that only for the OSE and WM regions we needed to drop the persistence parameter from the final models.

${ }^{8}$ The application of conditional copula theory requires that we condition both the mean and variance of each series on the same information. Any insignificant variables can be subsequently omitted.
} 
Table. 1 GARCH selection

\begin{tabular}{|c|c|c|c|c|c|c|}
\hline & $\mathrm{G}(1,1)-\mathrm{N}$ & GJR(1,1)-N & $\mathrm{G}(1,1)-t$ & GJR(1,1)- $t$ & $\mathrm{G}(1,1)$-skewed $t$ & $\operatorname{GJR}(1,1)$-skewed $t$ \\
\hline $\mathrm{N}$ & -751.42 & -746.48 & -746.56 & -741.55 & -741.46 & -736.44 \\
\hline YH & -785.83 & -781.17 & -781.72 & -777.26 & -776.67 & -772.30 \\
\hline NW & -849.14 & -849.22 & -849.01 & -847.41 & -844.48 & -843.00 \\
\hline EM & -807.41 & -802.34 & -805.73 & -800.70 & -805.63 & -800.86 \\
\hline WM & -810.08 & -811.07 & -810.92 & -808.65 & -808.66 & -806.34 \\
\hline EA & -767.87 & -762.87 & -771.64 & -766.58 & -769.96 & -764.89 \\
\hline OSE & -840.84 & -839.10 & -839.15 & -837.74 & -837.07 & -835.06 \\
\hline $\mathrm{OM}$ & -856.36 & -852.32 & -851.26 & -847.20 & -846.64 & -842.37 \\
\hline $\mathrm{L}$ & -775.42 & -770.34 & -770.66 & -765.59 & -766.88 & -761.77 \\
\hline SW & -823.28 & -818.36 & -827.83 & -823.65 & -822.95 & -818.70 \\
\hline $\mathrm{SC}$ & -794.71 & -795.51 & -791.68 & -791.13 & -787.35 & -786.69 \\
\hline NI & -678.41 & -674.08 & -676.18 & -671.26 & -671.11 & -666.19 \\
\hline WA & -739.86 & -735.77 & -736.70 & -732.03 & -731.88 & -727.25 \\
\hline UK & -906.53 & -901.67 & -904.20 & -899.41 & -900.55 & -895.85 \\
\hline SP & -367.26 & -362.37 & -372.31 & -367.18 & -369.09 & -363.99 \\
\hline
\end{tabular}

Note: Estimated Schwarz Information Criterion (SIC) values for various GARCH (denoted as G) and GARCH-GJR (denoted as GJR) specifications. The best model for each region is highlighted

As mentioned earlier, the validity of the copula function depends on the correct specification of the marginals. Along these lines, we perform a number of misspecification tests, as described earlier; their $p$-values are reported in Table 3. Panel A displays the results of the Lagrange-Multiplier tests of Diebold et al. (1998) for serial correlation, using 1 and 4 lags, in the first four moments of univariate residuals for house prices and share prices. Panel B reports the results of the Kolmogorov-Smirnov test and the likelihood ratio test of Berkowitz (2001). The former tests for uniformity whereas the latter tests jointly for uniformity and independence. Panel $\mathrm{C}$ reports the results from the 'Hit' regression tests of Patton (2006) which check for the correct specification of the density in different regions. The left tail (R1) corresponds to observations below the 25th quantile, the centre region (R2) is between the 25 th and 75th quantiles, and the right tail (R3) corresponds to the observations above the 75th quantile. The $p$-values associated with the tests, presented in the three panels of Table 3 , are, in the overwhelming majority of cases, well above 0.05 , indicating that the marginals are correctly specified.

\section{Constant Copulas}

As discussed earlier, different copulas imply different dependence structures. For the models that assume that the dependence between the stock and housing markets is constant over time, we consider seven different copulas: four asymmetric copulas (Clayton, rotated Gumbel, rotated Clayton, Gumbel) and three symmetric copulas (Normal, Frank, Student's $t$ ). The Clayton and rotated Gumbel copulas are suitable for variables that exhibit greater dependence in the left tail as compared to the right tail, 
while the Gumbel and rotated Clayton copulas are suitable for variables that exhibit stronger right tail dependence. The Normal, Frank and Student's $t$ copulas represent a symmetric dependence structure, either with zero (Normal, Frank) or positive (Student's $t$ ) tail dependence.

We start by looking at the estimation results for the dependence structure between the stock and housing markets at the national level as well as at the regional level. The constant copula parameter theta $(\theta)$, the dependence measures Kendall's tau $(\tau)$ and Spearman's rho $(\rho)^{10}$, as well as three measures of fit, namely the (negative) loglikelihood (LL), the Akaike Information Criterion (AIC) and the SIC, are reported in Table 4. The models for the UK and all the regions show that $\theta, \tau$, and $\rho$ are always positive, indicating a positive association between house prices and share prices. Using the measures of fit (LL, AIC and SIC), we can assess which copula best describes the data in each case. The lower the value of these statistics, the better the fit of the model. All the measures of fit are in agreement in identifying the best copula in each case.

For the national UK housing market, the rotated Gumbel copula ranks first. Such a result implies that the housing and stock markets are more likely to crash, rather than boom, together. In other words, if one of the markets is performing badly over a given quarter, the other market is also likely to experience a significant decline over the same period. This finding mirrors the empirical results of Knight et al. (2005) who report that the relationship between real estate indices and the aggregate stock market is characterised by stronger left tail dependence. Moreover, our study provides novel insights into the literature that has reported a positive association between the housing and stock markets (Sutton 2002, and Eichholtz and Hartzell 1996). In particular, our results show that their dependence is stronger during market downturns which will further exacerbate any contagion effects.

To illustrate the results of our copula estimations, we follow Zimmer (2012) and Ho et al. (2016) and we graphically represent the relationship between the national housing market and stock market using conditional probabilities, defined as:

$$
\begin{gathered}
C P_{t}^{-}(k)=\operatorname{Pr}\left(z_{H P, t}<k \mid z_{S P, t}<k\right)=\frac{\widehat{C}_{t}\left(\widehat{F}_{t}(k), \widehat{G}_{t}(k) ; \widehat{\theta}_{t}\right)}{\widehat{G}_{t}(k)} \\
C P_{t}^{+}(k)=\operatorname{Pr}\left(z_{H P, t}>k \mid z_{S P, t}>k\right)=\frac{1-\widehat{F}_{t}(k)-\widehat{G}_{t}(k)+\widehat{\mathrm{C}}_{t}\left(\widehat{F}_{t}(k), \widehat{G}_{t}(k) ; \widehat{\theta}_{t}\right)}{1-\widehat{G}_{t}(k)}(10)
\end{gathered}
$$

$C P_{t}^{-}$is the probability that the filtered house price return, represented by the standardized residual $z_{H P, t}$ of the relevant GARCH model, will be lower than a reference level $k$, given that the standardized residual $z_{S P, t}$, corresponding to the filtered stock price index return, is lower than $k$. Similarly, $C P_{t}^{+}$is the probability that the filtered house price return will exceed $k$, conditional on the filtered stock price index return being higher than $k$. It is worth noting that calculating conditional probabilities by evaluating the

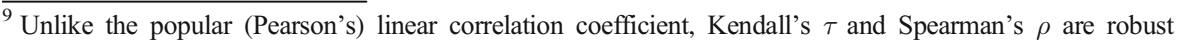
measures of association when the underlying dependence is nonlinear.
} 


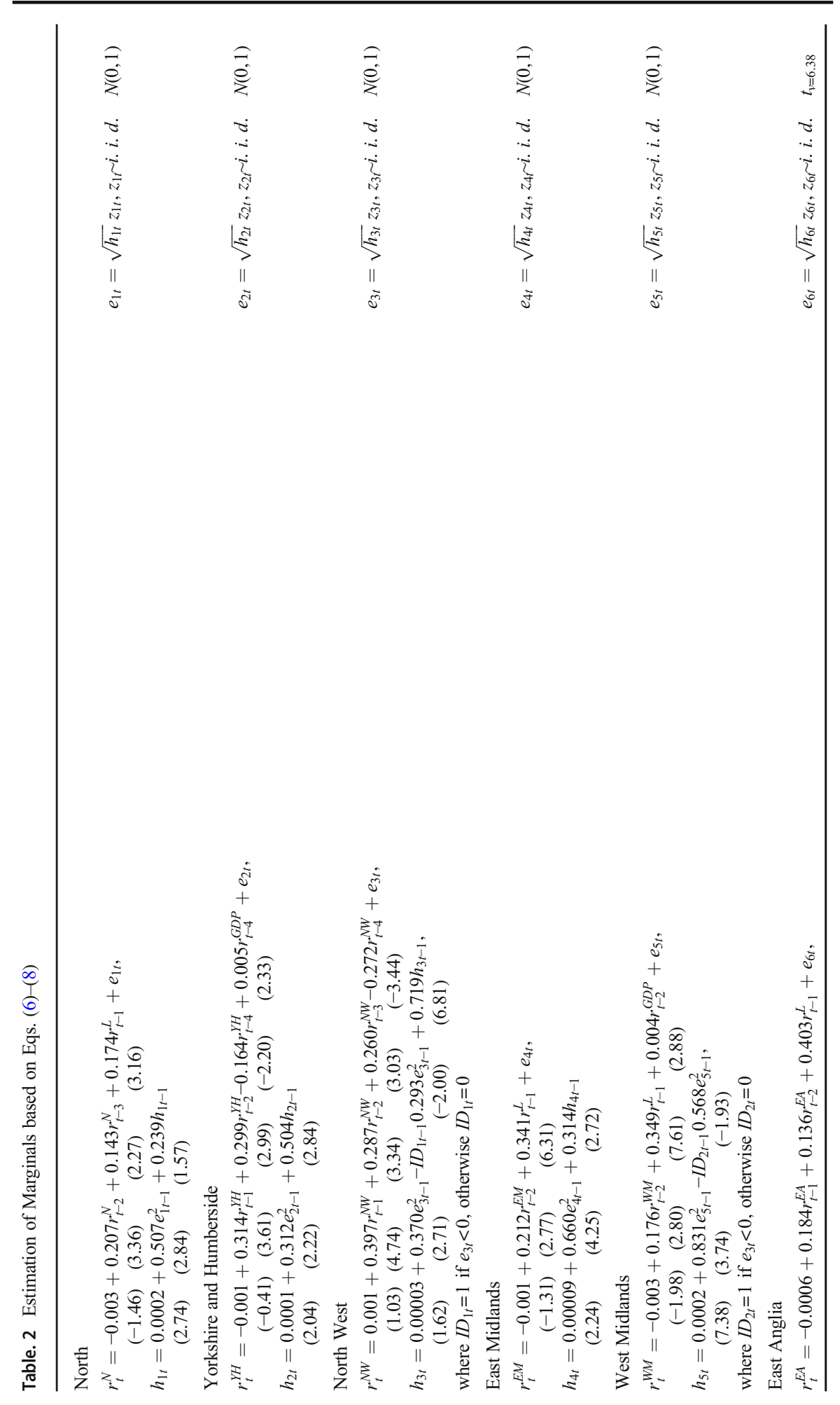



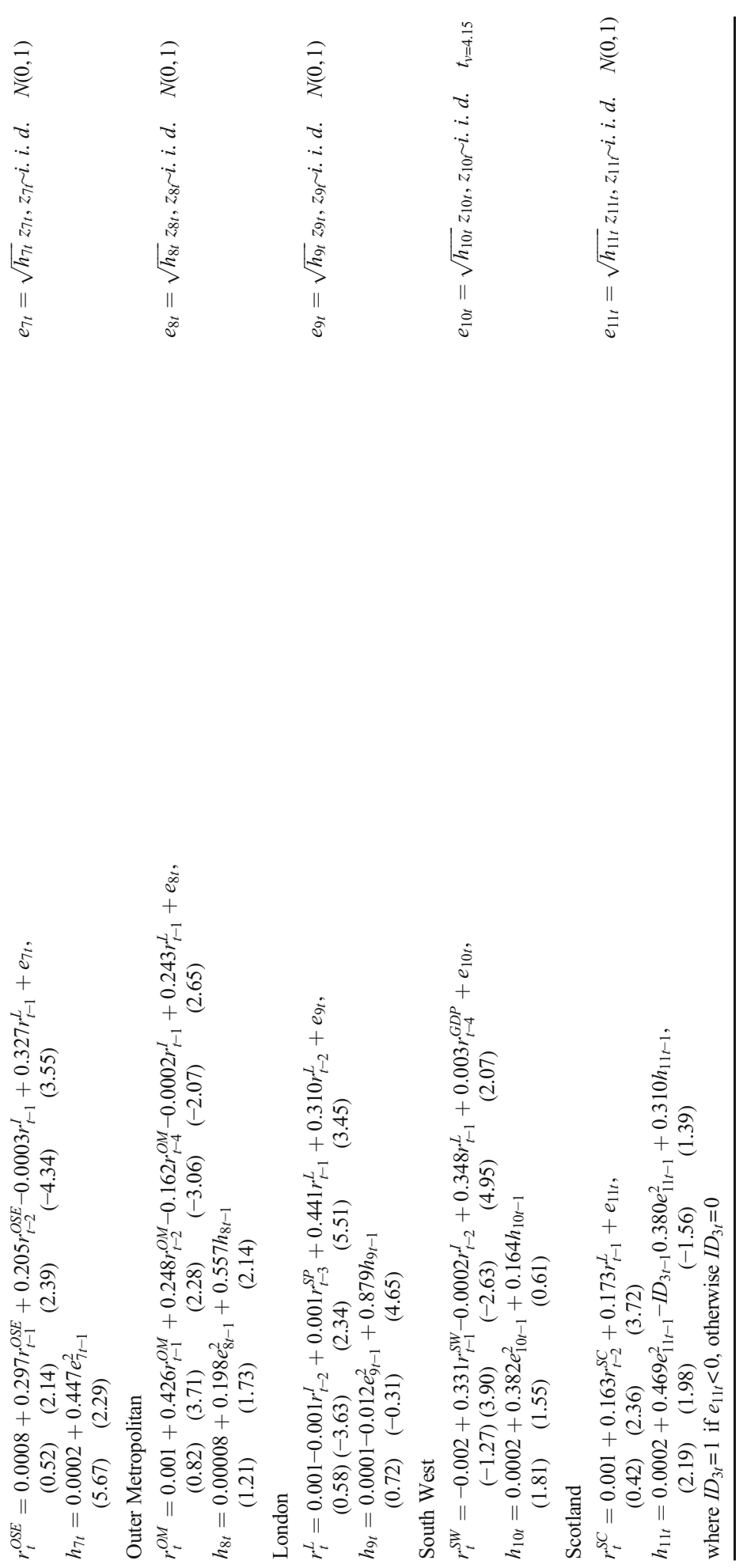


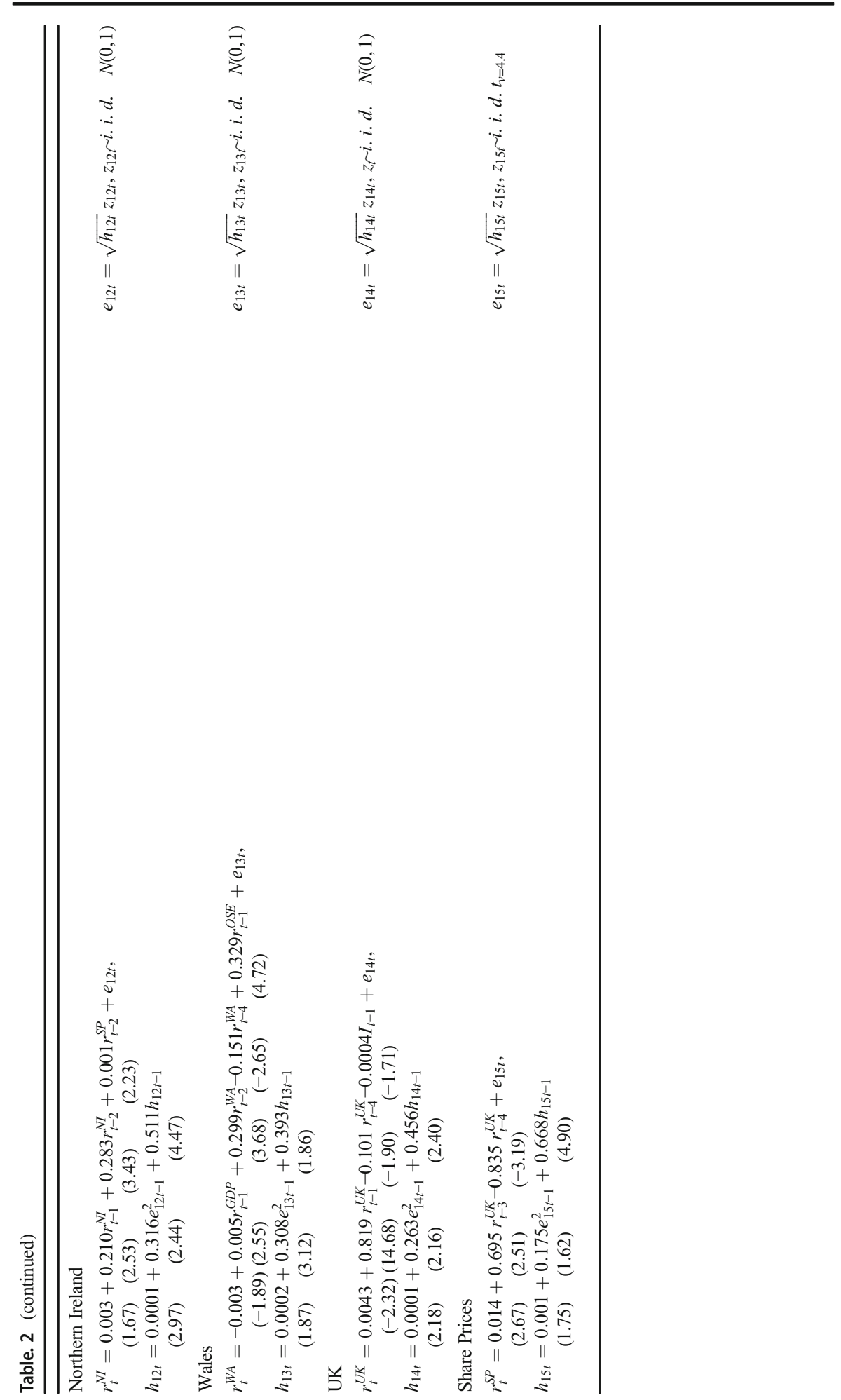


Table. $3 p$-values of misspecification tests

Panel A: Moment independence tests.

House prices conditional on FTSE (1 lag)

$\begin{array}{lllllllllllllll} & \text { N } & \text { YH } & \text { NW } & \text { EM } & \text { WM } & \text { EA } & \text { OSE } & \text { OM } & \text { L } & \text { SW } & \text { SC } & \text { NI } & \text { WA } & \text { UK } \\ \text { 1st } & 0.17 & 0.56 & 0.28 & 0.65 & 0.64 & 0.84 & 0.85 & 0.72 & 0.80 & 0.59 & 0.15 & 0.84 & 0.76 & 0.33 \\ \text { 2nd } & 0.68 & 0.13 & 0.32 & 0.48 & 0.34 & 0.34 & 0.94 & 0.81 & 0.78 & 0.93 & 0.33 & 0.39 & 0.87 & 0.56 \\ \text { 3rd } & 0.24 & 0.19 & 0.11 & 0.52 & 0.31 & 0.89 & 0.62 & 0.97 & 0.71 & 0.29 & 0.70 & 0.66 & 0.72 & 0.16 \\ \text { 4th } & 0.70 & 0.07 & 0.49 & 0.46 & 0.27 & 0.52 & 0.70 & 0.79 & 0.74 & 0.94 & 0.50 & 0.37 & 0.38 & 0.39\end{array}$

FTSE conditional on house prices (1 lag)

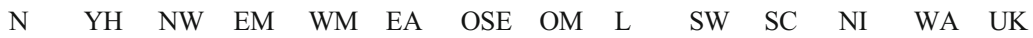

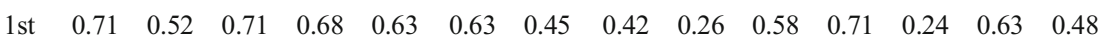

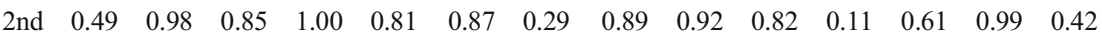

$\begin{array}{lllllllllllllll}\text { 3rd } & 0.89 & 0.62 & 0.91 & 0.78 & 0.86 & 0.99 & 0.93 & 0.91 & 0.57 & 0.93 & 0.98 & 0.15 & 0.92 & 0.99\end{array}$

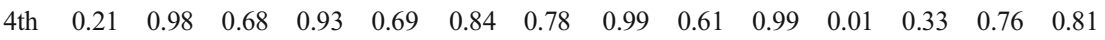

House prices conditional on FTSE (4 lags)

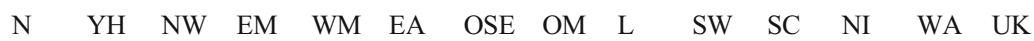

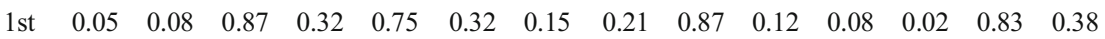

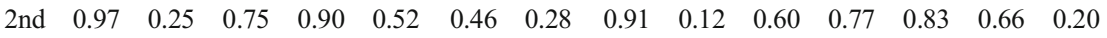

$\begin{array}{llllllllllllllll}3 \text { 3rd } & 0.04 & 0.08 & 0.74 & 0.11 & 0.66 & 0.69 & 0.11 & 0.30 & 0.86 & 0.38 & 0.52 & 0.05 & 0.59 & 0.22\end{array}$

$\begin{array}{lllllllllllllll}\text { 4th } & 0.90 & 0.27 & 0.79 & 0.96 & 0.64 & 0.45 & 0.45 & 0.86 & 0.03 & 0.94 & 0.84 & 0.61 & 0.49 & 0.48\end{array}$

FTSE conditional on house prices (4 lags)

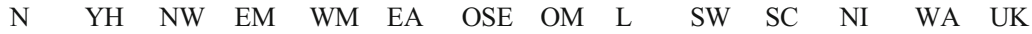

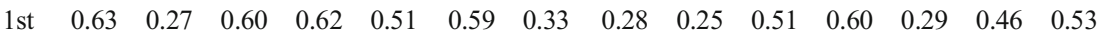

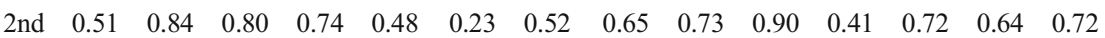

$\begin{array}{lllllllllllllll}\text { 3rd } & 0.45 & 0.08 & 0.45 & 0.54 & 0.54 & 0.32 & 0.57 & 0.31 & 0.45 & 0.47 & 0.43 & 0.13 & 0.39 & 0.60\end{array}$

$\begin{array}{lllllllllllllll}\text { 4th } & 0.37 & 0.83 & 0.70 & 0.58 & 0.41 & 0.68 & 0.75 & 0.78 & 0.50 & 0.87 & 0.20 & 0.64 & 0.37 & 0.73\end{array}$

Panel B. Kolmogorov-Smirnov (KS) and Berkowitz (BK) tests

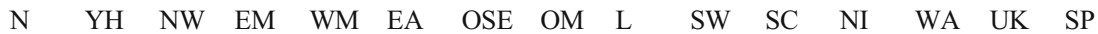

$\begin{array}{llllllllllllllll}\text { KS } & 0.56 & 1.00 & 0.66 & 0.75 & 0.82 & 0.97 & 0.54 & 1.00 & 0.84 & 0.73 & 0.63 & 0.98 & 0.84 & 0.96 & 0.98\end{array}$

$\begin{array}{llllllllllllllll}\text { BK } & 0.85 & 0.96 & 0.99 & 0.75 & 0.91 & 0.88 & 0.97 & 0.96 & 0.99 & 0.92 & 0.73 & 0.99 & 0.96 & 0.66 & 0.89\end{array}$

Panel C. 'Hit' regression tests

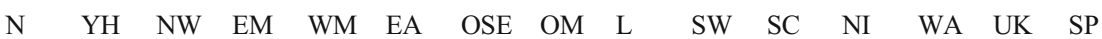

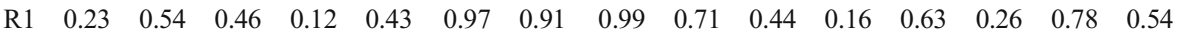

$\begin{array}{llllllllllllllll}\text { R2 } & 0.31 & 0.88 & 0.22 & 0.23 & 0.36 & 0.69 & 0.79 & 0.63 & 0.65 & 0.55 & 0.89 & 0.88 & 0.20 & 0.38 & 0.30\end{array}$

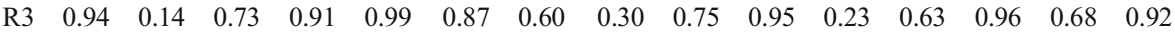

distributions of the standardized residuals at fixed levels of $k$ is a very convenient representation. In particular, this implies that $C P_{t}^{-}\left(C P_{t}^{+}\right)$shows the probability that the housing price return will be lower (higher) than $k$ standard deviations away from its mean, given that the stock market return is lower (higher) than $k$ standard deviations 


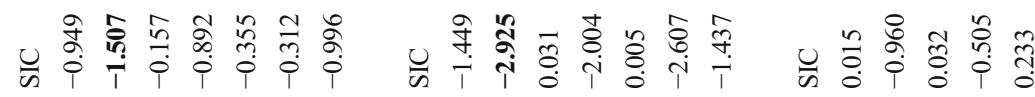

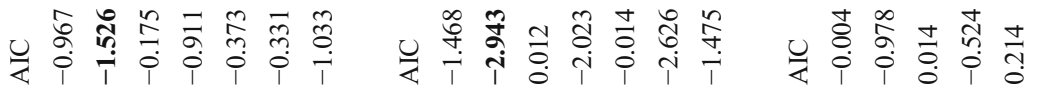

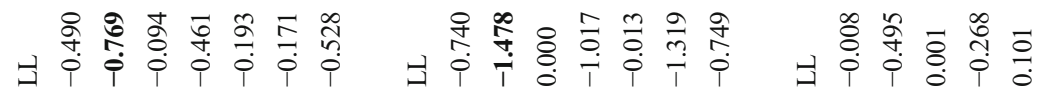

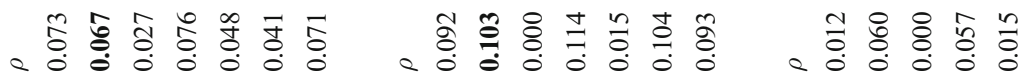

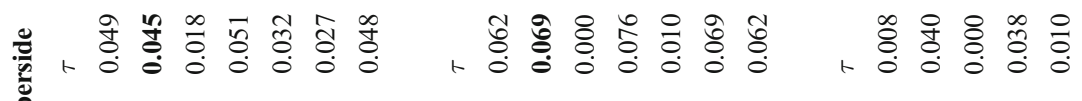

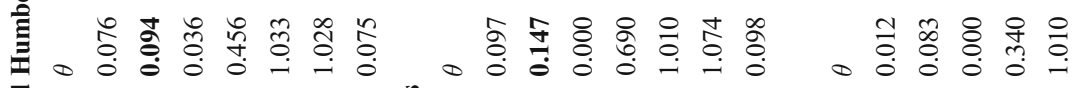

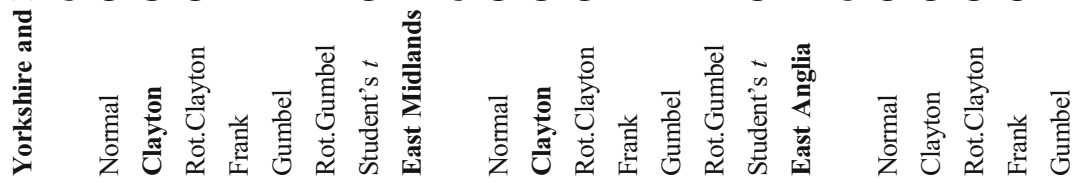

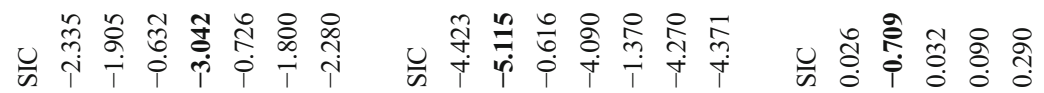

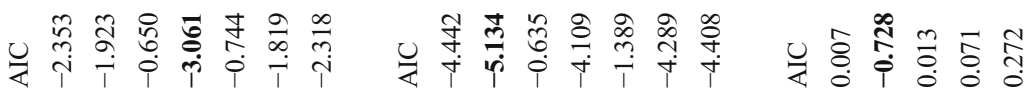

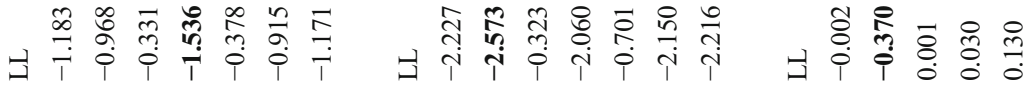

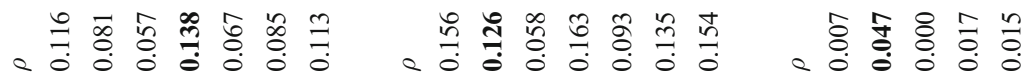

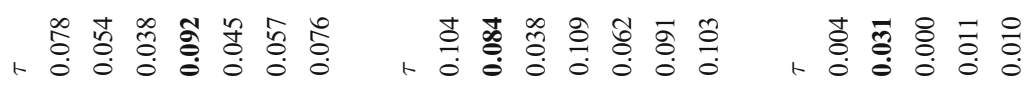

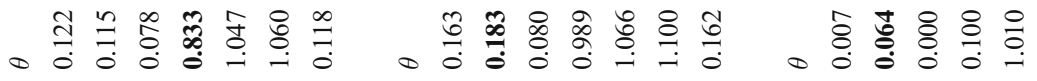

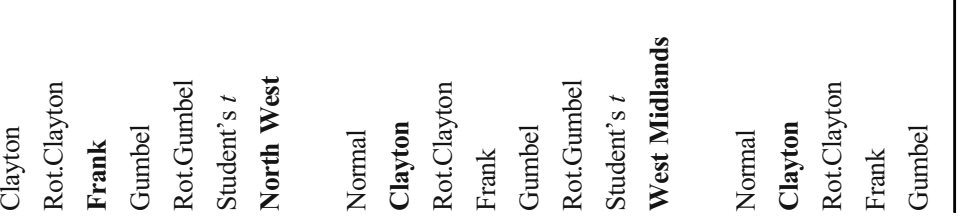




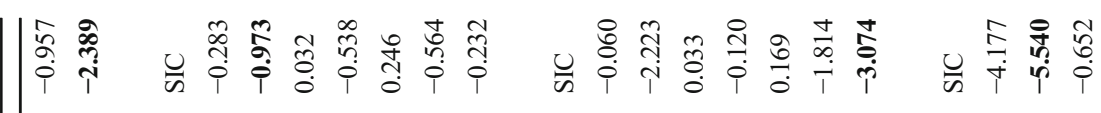

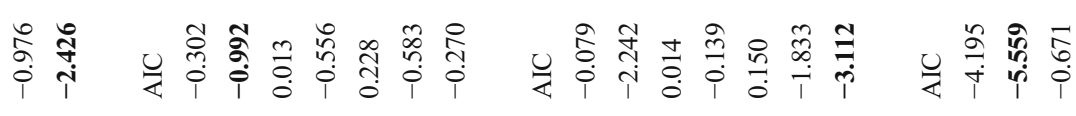

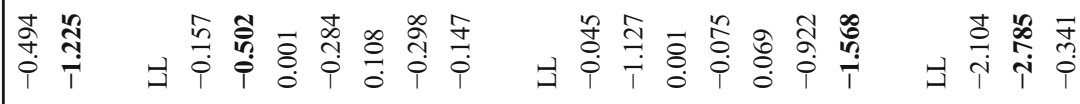

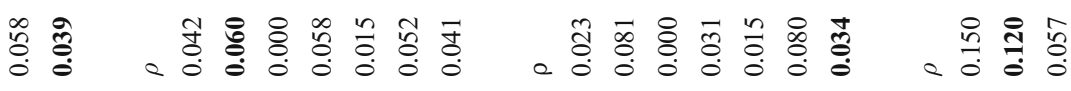

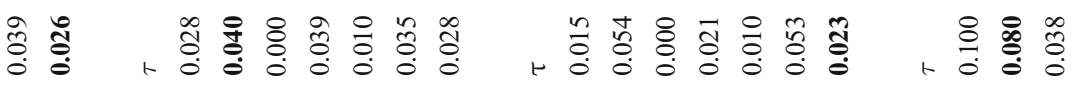

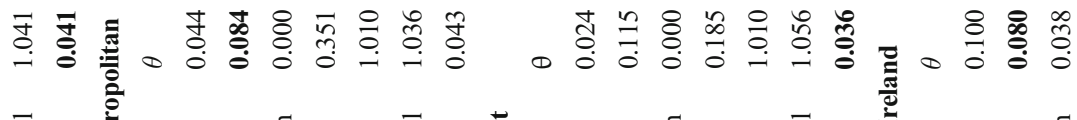

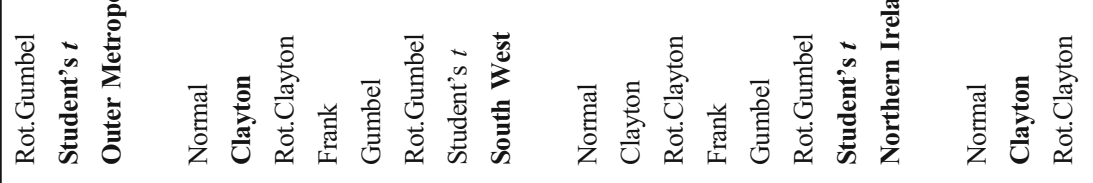

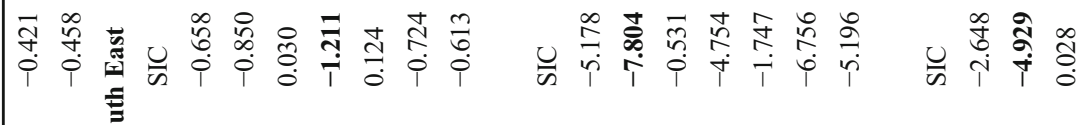

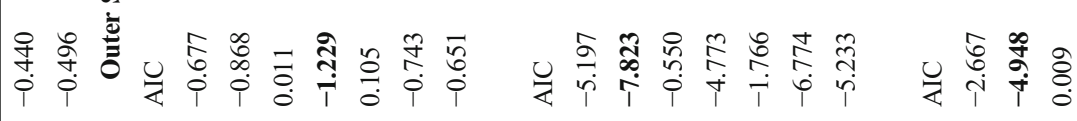

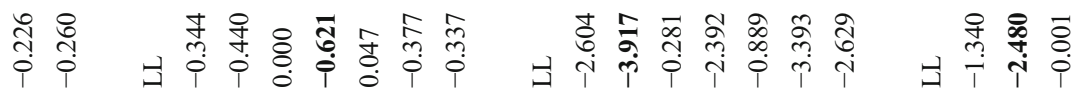

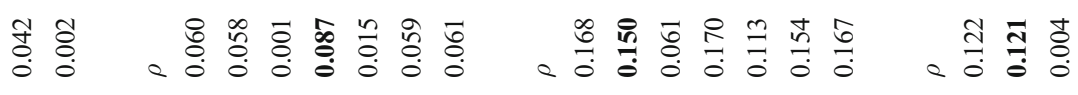

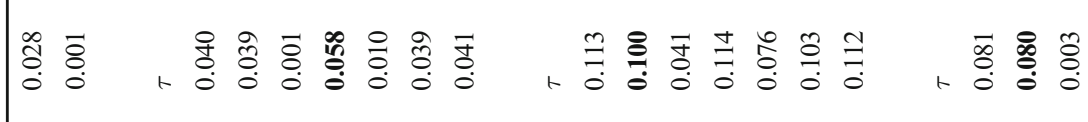

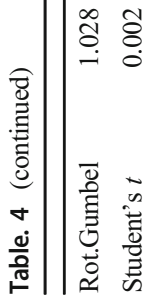

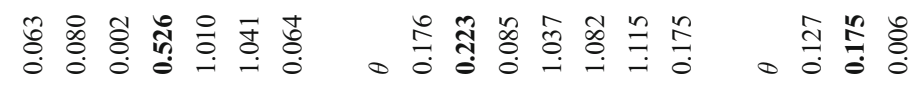

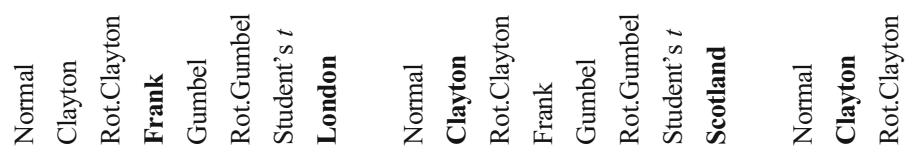




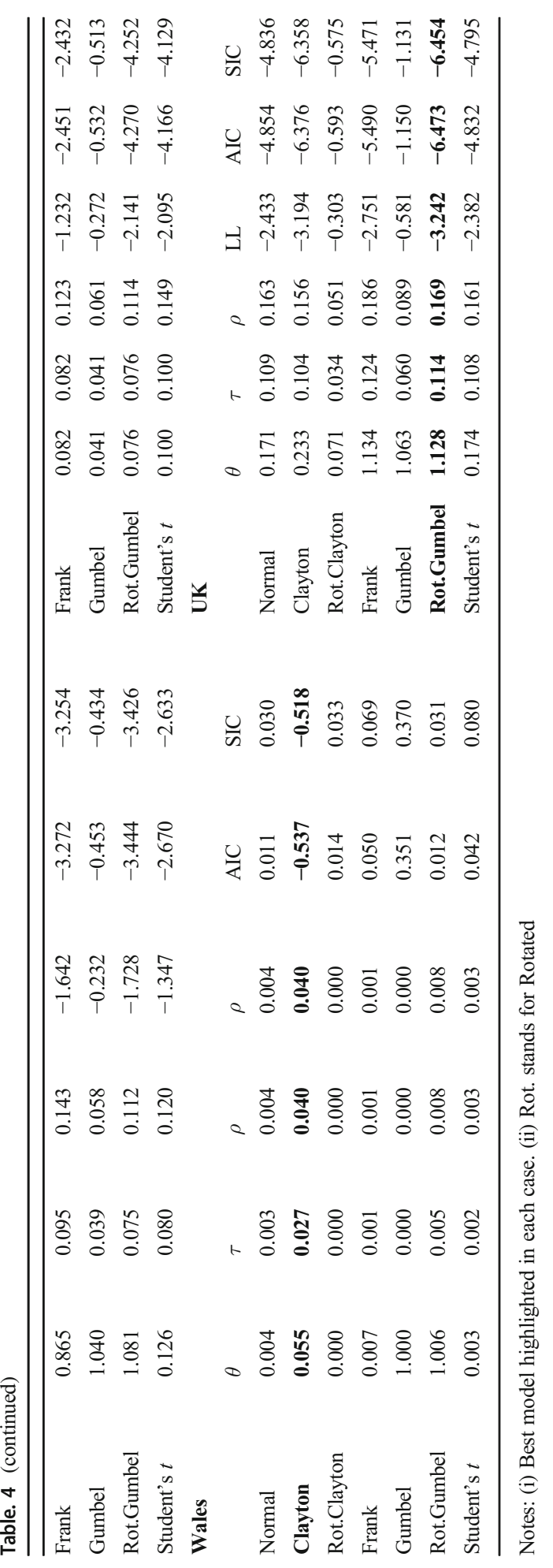


away from its mean. Simply put, if we assume that the stock market will experience a crash (boom) in the next quarter, these conditional probabilities show the likelihood that in the same period the housing market will also experience a crash (boom) of a similar magnitude ${ }^{11}$.

Figure 1 displays the conditional probabilities implied by the best fitting copula specification at the national level, the rotated Gumbel, against those of the Normal copula which exhibits no tail dependence and serves as a benchmark. As Fig. 1 shows, while the likelihood of joint booms, displayed on the right side of the graph, in the two markets is fairly similar in both models, the Normal copula severely underestimates the probability of joint extreme crashes which is displayed on the left side of the graph. For policymakers and financial institutions that are particularly worried about the linkages between the housing and equity markets during periods of financial turmoil, this result highlights the risk of using an inappropriate model.

The empirical results for the regional analysis largely resemble those at the national level. Specifically, for nine of the 13 regions (YH, NW, EM, WM, OM, L, SC, NI, WA) the Clayton copula, which also exhibits left tail dependence, provides the best fit to the data. For these regions, as the conditional probabilities in Fig. 2 depict, the benchmark Normal copula always underestimates the risk of joint crashes, often by a wide margin. On the other hand, it overestimates the likelihood of joint price booms but, in the majority of cases, only by a rather narrow margin.

For EA and SW, the dependence between the stock and housing markets is best captured by the Student's $t$ copula which has symmetric tail dependence, indicating that joint crashes and booms are equally likely. This is illustrated by the conditional probabilities in Fig. 3 which show that the probabilities of joint crashes and joint booms are higher than those implied by the benchmark Normal copula.

For $\mathrm{N}$ and OSE, the Frank copula provides the best fit of their relationship with the stock market, implying that there is no tail dependence. This is also portrayed by the conditional probabilities in Fig. 4.

\section{Time-Varying Copulas}

In the previous section, the dependence between the housing and stock markets was assumed to be constant over time. In this section, we allow the degree of dependence to be timevarying following the GAS copula dynamics introduced in Creal et al. (2013), as presented earlier. For this part, we focus on three conditional copula models with distinct dependence characteristics: the Gumbel copula (right tail dependence), the Normal copula (symmetric with no tail dependence) and the rotated Gumbel copula (left tail dependence). The estimated parameters, together with the LL, AIC, and SIC statistics are displayed in Table 5.

From these empirical results, a key finding of our study emerges. The dependence between the housing market at the national level and the stock market is both asymmetric and time-varying. Using, for example, SIC as a measure of fit, we find that the time-varying rotated Gumbel copula model, which implies stronger left tail dependence that varies across time, ranks favourably against any other, constant or time-varying, copula model. We also

\footnotetext{
${ }^{10}$ It is important to clarify these joint crash/boom probabilities are contemporaneous, i.e. they correspond to price changes over the same period. As such, they are not driven by lead-lag effects between the two variables, which have already been taken into account when the marginal distributions were modelled.
} 


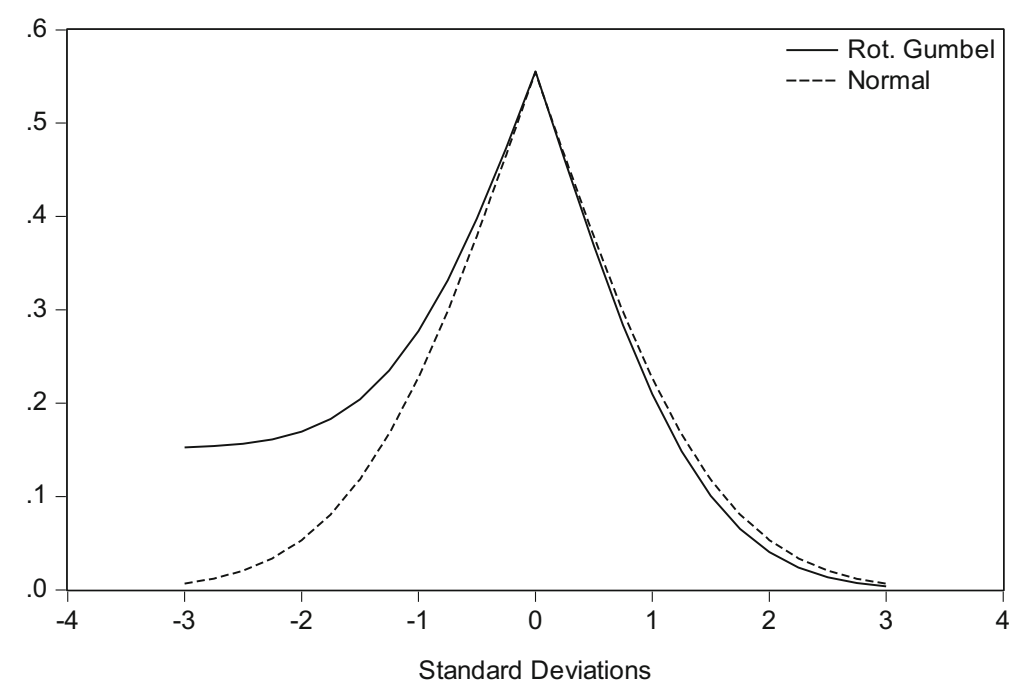

Fig. 1 Conditional probabilities at the aggregate level

note that the null hypothesis of constant dependence is rejected at the 5\% level. In particular, given that the best constant copula model (rotated Gumbel) is nested in the time-varying specification, a standard likelihood ratio test reveals that the constant copula model is rejected with a $p$ value of $4 \%$.

Our regional analysis provides additional interesting insights. For all regions, when the SIC statistics of the best constant and time-varying copula models are compared, timevarying specifications always rank higher than the constant ones. This widespread
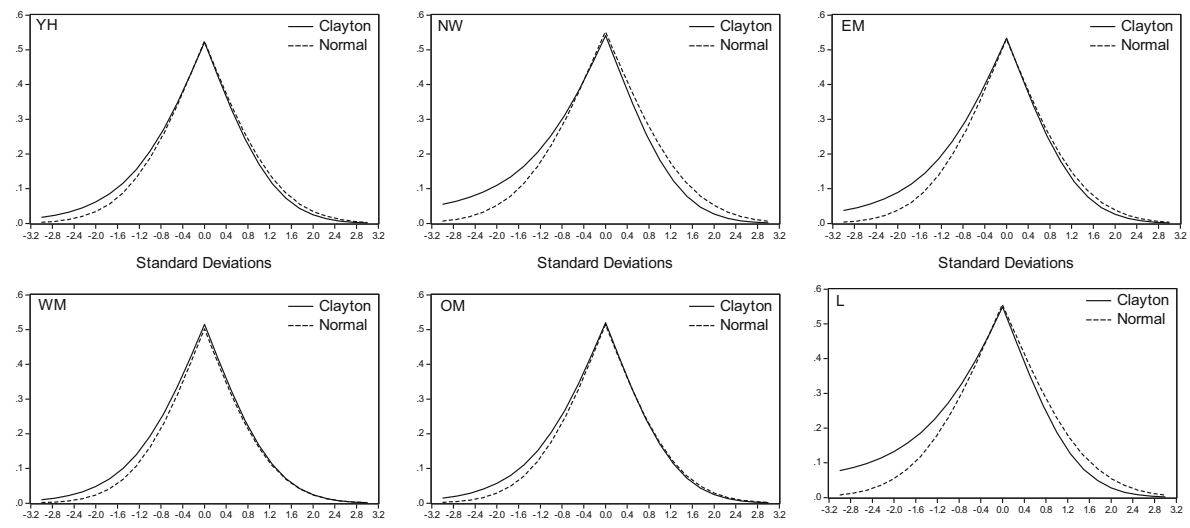

Standard Deviations
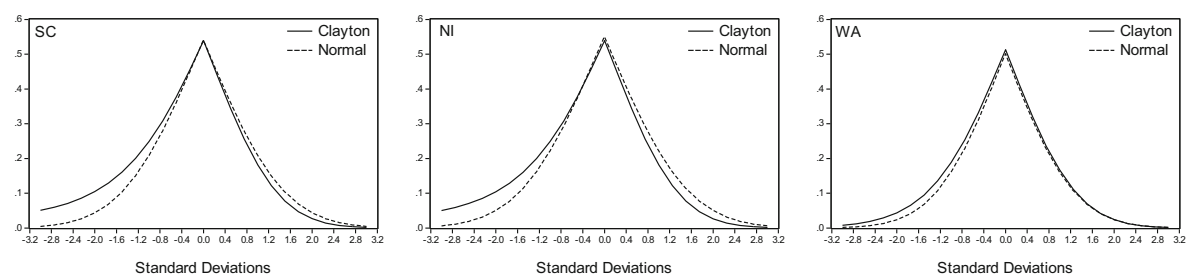

Fig. 2 Conditional probabilities for regions that exhibit stronger left tail dependence 

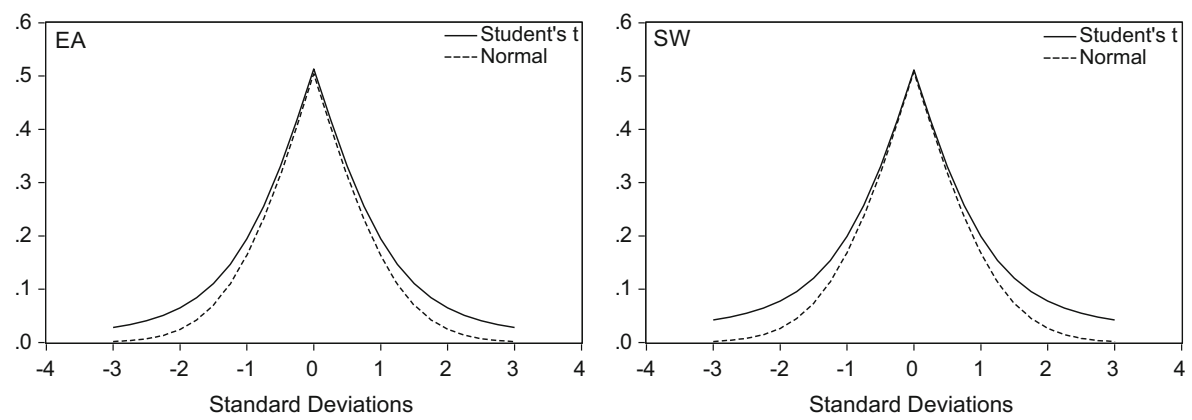

Fig. 3 Conditional probabilities for regions that exhibit Student's $t$ copula (symmetric) tail dependence

consistency in these findings reinforces the belief that the relationship between the stock market and the housing market evolves over time. Within the class of time-varying copula models, we find that most regions are compatible with a Gaussian dependence paradigm. In particular, for eight regions (YH, NW, EM, WM, EA, OSE, L, WA) the preferred model is the time-varying Normal copula. The remaining five regions (N, OM, $\mathrm{SW}, \mathrm{SC}, \mathrm{NI})$ share the same dynamics as those of the national housing market, as their dependence with the equity market is time-varying, asymmetric and best described by the time-varying rotated Gumbel copula.

\section{Further Insights into our Findings}

Our findings raise important questions for both policymakers and market participants. How much should one be concerned if the wrong model is used? To this end, we attempt to obtain better insights with respect to the practical implications of our findings by once again looking at conditional probabilities. In the case of the constant copulas, the conditional probability figures represented the behaviour of the model for the whole sample over various values of $k$. In the case of time-varying copulas, the conditional probabilities will evolve with time. As an illustration, in Fig. 5, we show how the best performing model at the national level, the time-varying rotated Gumbel copula, compares against some benchmark models for $k=2$. We have selected $k=2$ as a reference point for joint crashes/booms, as observations beyond this level are more relevant for studying significant price swings. To better understand the risk ramifications, one has to approach this question by examining various factors that influence the dependence structure between the two markets. The benchmark models we use reflect
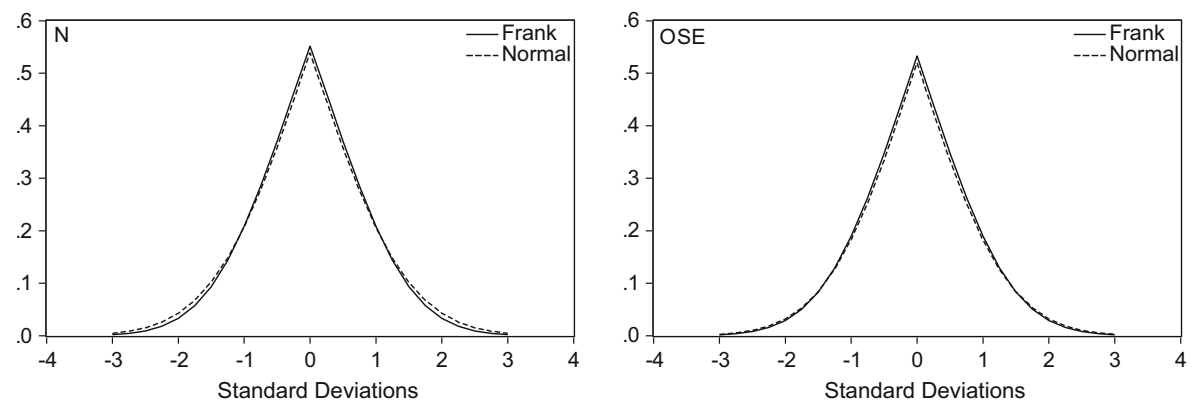

Fig. 4 Conditional probabilities for regions that exhibit Frank copula (symmetric) tail dependence 


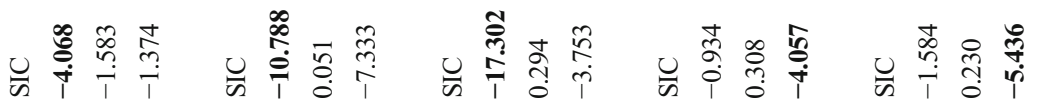

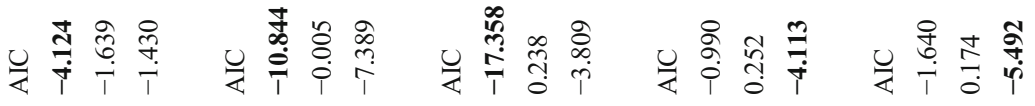

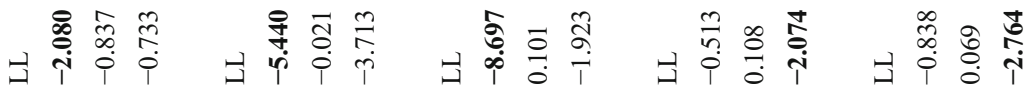

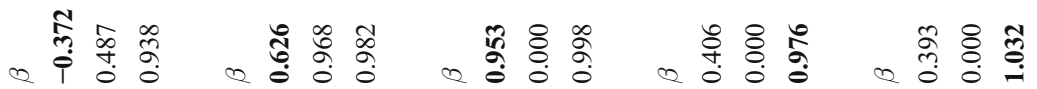

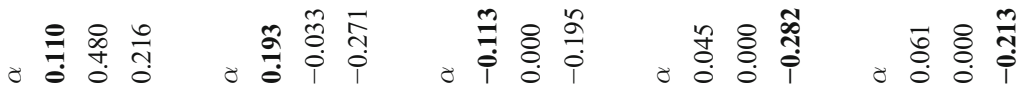

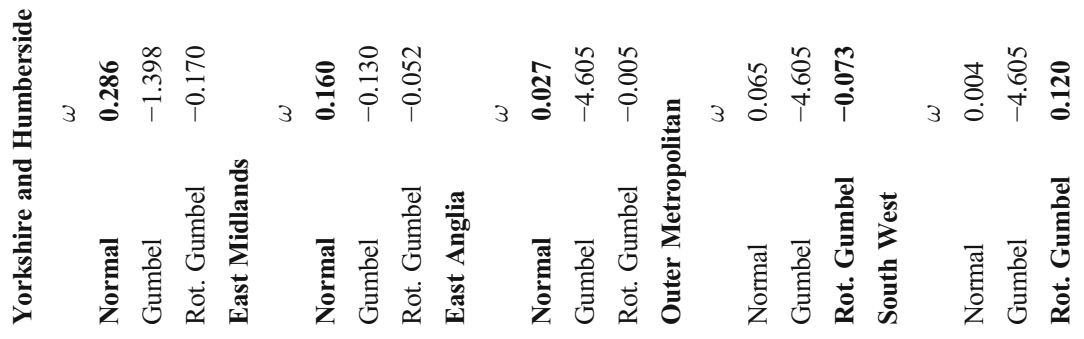

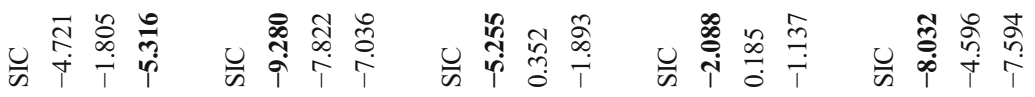

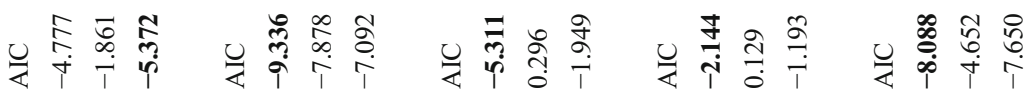

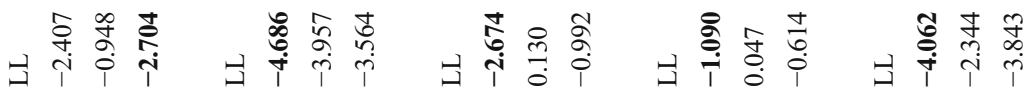

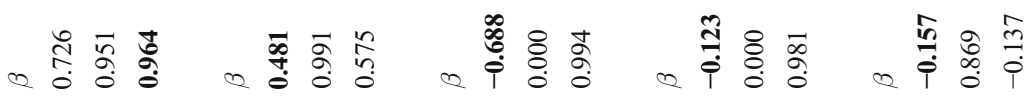

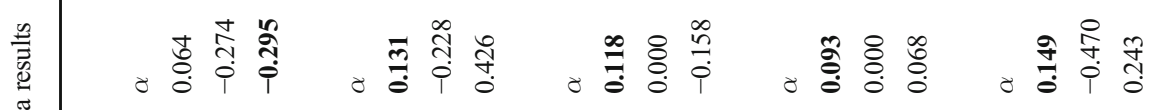

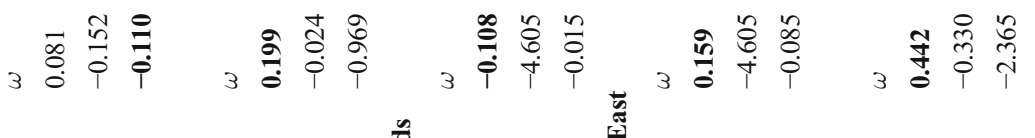

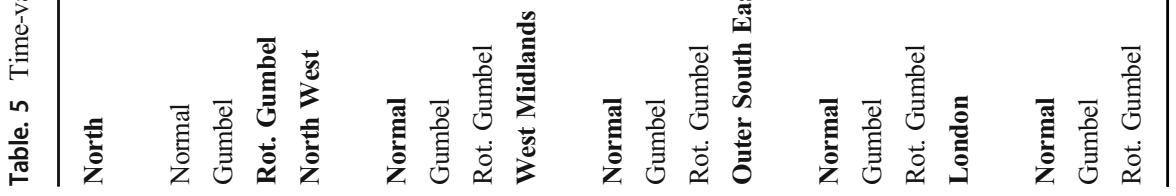




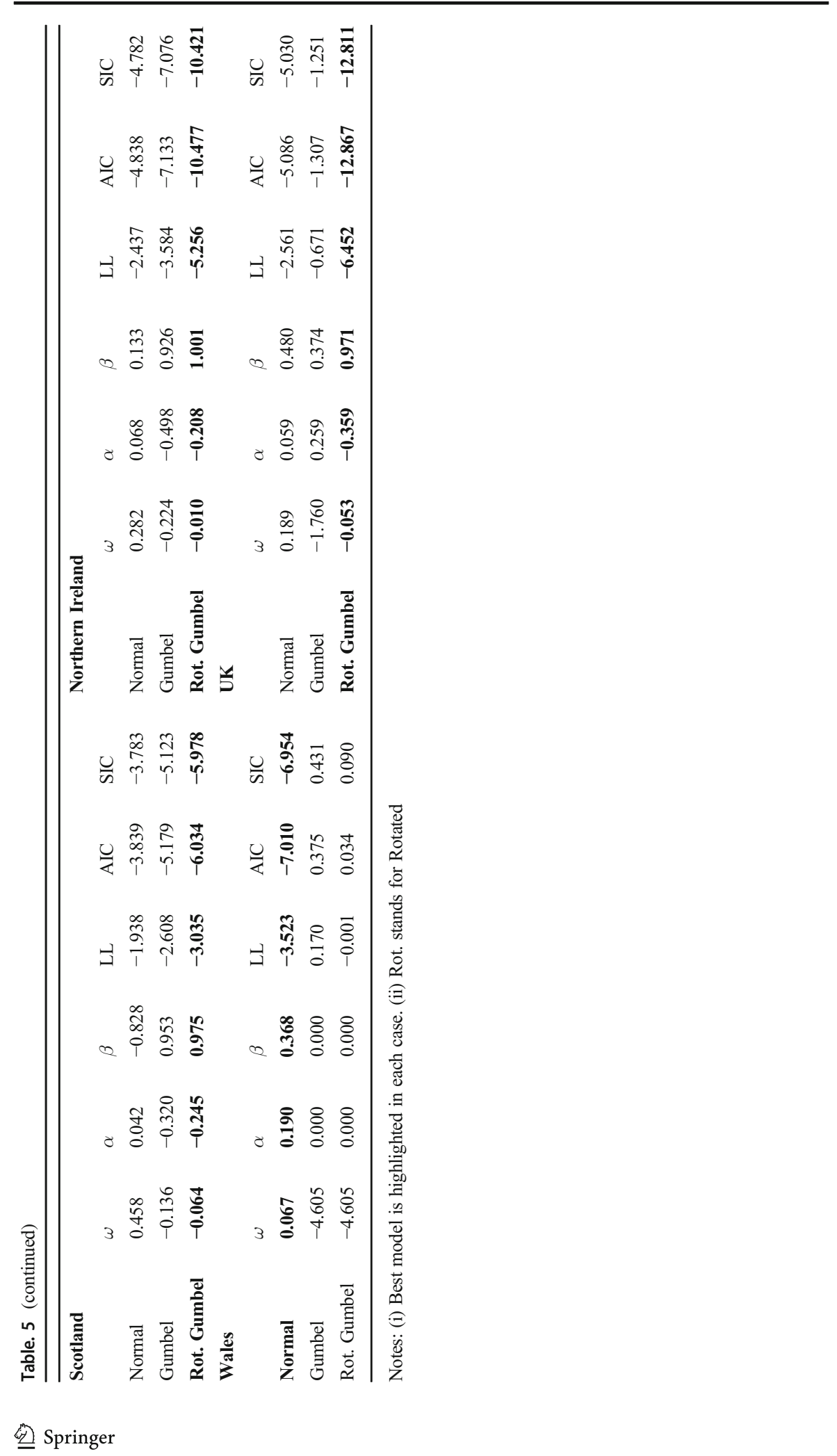




\section{a}

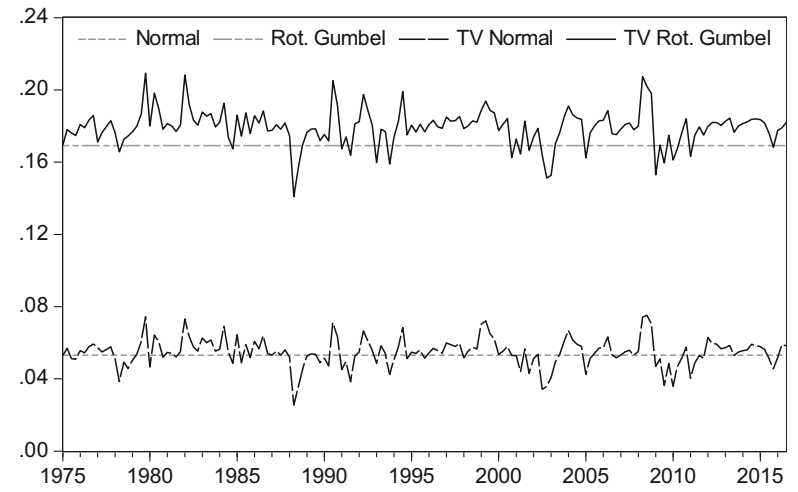

b

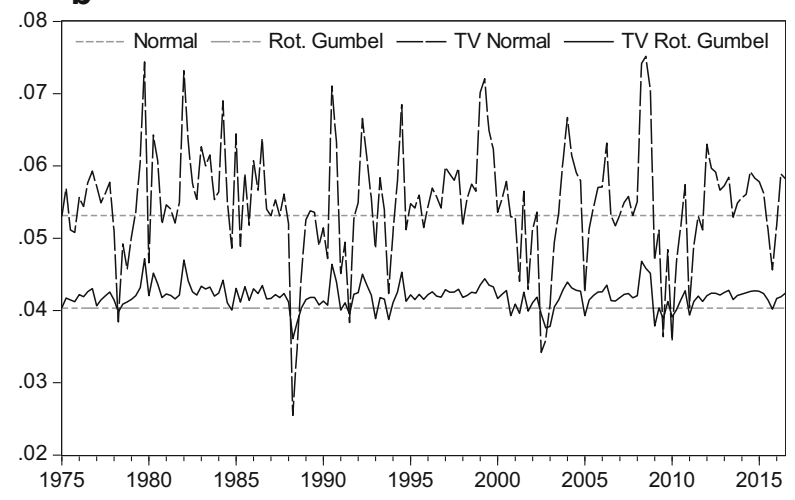

Fig. 5 Conditional probabilities for joint booms and crashes. Panel a: Conditional probabilities for joint crashes. Panel b: Conditional probabilities for joint booms

the potential omission of important defining characteristics in the dependence structure. The benchmark models are: (i) the constant Normal copula model, (ii) the best constant copula model, which in this case is the rotated Gumbel copula and (iii) the time-varying Normal copula model. Given that the best model at the national level is a time-varying asymmetric copula, using a constant Normal copula would imply that tail dependence and time-variation are being ignored. Using the best constant copula implies that time-variation is being ignored, while using the time-varying Normal copula implies that tail dependence is being ignored. Panel A of Fig. 5 shows the conditional probabilities for joint crashes $\left(\mathrm{CP}^{-}\right)$, while those corresponding to joint booms $\left(\mathrm{CP}^{+}\right)$are displayed in Panel B.

Starting with Panel A, with reference to the conditional probabilities of the best model, the time-varying rotated Gumbel copula, we can see that both the constant and the timevarying Normal copula significantly underestimate the conditional probabilities of joint crashes. The negative consequences of incorrectly relying on the constant rotated Gumbel copula appear more benign. We can quantify the divergence between the models by finding the difference in the mean conditional probabilities of the best model and the alternative model. The conditional probability difference with the constant Normal copula model is $12.6 \%$ on average, implying that ignoring time-variation and tail dependence leads to the likelihood of a joint crash being substantially underestimated. Ignoring tail 
dependence by using the time-varying Normal copula leads to an underestimation of risk by $12.43 \%$ on average. The difference between the best copula model and the best constant copula model is relatively modest; more specifically, ignoring time-variation in the dependence structure while taking tail dependence into account would lead to an underestimation of the risk of a joint crash by $0.99 \%$ on average. This underscores a key finding of our empirical study about the relationship between the national housing and stock markets, namely that accommodating left tail dependence is of the essence for properly measuring joint crash risk.

For the case of joint booms in the two markets, the implications of relying on the wrong copula model are much more innocuous. As shown in Panel B of Fig. 5, the Normal copula models exaggerate the probabilities of joint booms, although they are not very far from those implied by the optimal model. The mean conditional probability differences between the optimal copula and the constant and time-varying Normal copulas are $-1.12 \%$ and $-1.28 \%$ respectively. The negative signs indicate that the probabilities of joint booms are overestimated by the Normal copula models. The difference in the conditional probabilities between the optimal model and the best constant copula model is $0.16 \%$ on average.

For our discussion on the regional level findings, we will continue using the difference in conditional probabilities based on benchmark models which reflect potential omissions of important defining characteristics in the dependence structure. The best models in each case, and the difference in conditional probabilities, are provided in Panels A and B of Table 6 for joint crashes and booms respectively. The first row in the panels of the table lists the optimal model for each region. The subsequent rows provide the average of the difference in conditional probabilities between the optimal model and (i) the constant Normal copula, (ii) the best constant copula and (iii) the time-varying Normal copula respectively. Numbers closer to zero indicate a minimal difference between the best model and the alternative model. In some cases the difference will be zero; this happens when the best model is the same as the alternative model. Positive numbers indicate that the likelihood of an extreme event (either joint crash or joint boom) is being underestimated, while negative numbers indicate that the likelihood of an extreme event is being overestimated. A number of interesting findings emerge from these tables, many of which reinforce our results at the national level.

(i) Using the wrong model leads to either an overestimation or an underestimation of the probabilities of joint crashes and booms, which, in some cases, is quite high and can potentially have severe consequences for policymakers and market participants alike. For instance, for the region North in Panel A, the differences in the conditional probabilities with the three alternative models are $12.31 \%, 13.27 \%$ and $11.65 \%$ on average. In all the three alternative scenarios the probability of a joint crash is severely underestimated. An example of overestimating joint crash risk is provided by London in Panel A. The appropriate model is a time-varying Normal copula but if the Clayton copula is used, the risk of a joint crash with the stock market would be overestimated by $6.9 \%$ on average.

(ii) In cases where the optimal model is a time-varying version of the best constant copula, the difference between the conditional probabilities tend to be relatively small. In Panel A, for example, the best model for $\mathrm{YH}$ is the time-varying Normal copula but if instead a constant Normal copula was used, the underestimation of a joint crash would be $0.8 \%$ on average. This is in sharp contrast to, for instance, OM where the best model is a time-varying rotated Gumbel, but if a constant Normal copula was used instead, joint crash risk would be underestimated by $10.96 \%$ on average. 


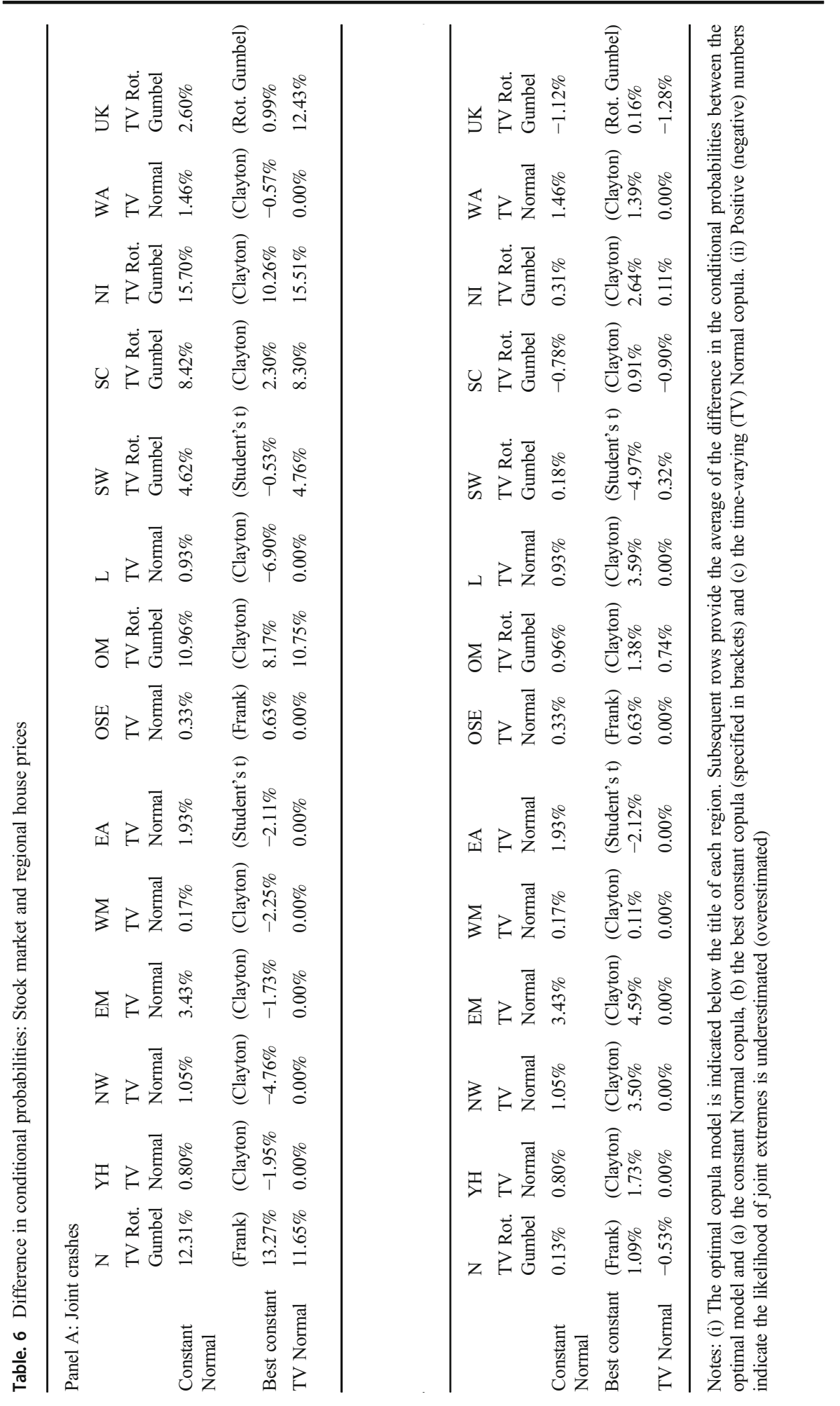


(iii) We find that generally if the wrong model is used, the differences in the conditional probabilities are larger for joint crashes as compared to joint booms. This reflects the fact that left tail dependence is more prevalent in the data compared to right tail dependence.

(iv) Even if the same copula model is appropriate for two regions, and the same incorrect assumption is employed for both cases, the errors can be markedly different. For example, both EM and OSE have the time-varying Normal copula as the best model but if the constant Normal copula model was used for these regions, joint crash risk would be underestimated on average by $3.43 \%$ and $0.33 \%$, respectively. In other words, ignoring time-variation has a different impact on each of these cases. This simply reflects the fact that the degree of dependence, captured by the parameter of the time-varying Normal copula, evolves differently across time for each of these regions.

Overall, these results add support to the growing literature that highlights the importance of the regional analysis of housing markets. We can clearly see from these results that the characteristics of the UK regions are different to those of the national level and therefore any policies, targeting the housing market, devised at the national level will not necessarily have the desired effect across all regions.

\section{Dependence Structure between London Prices and Other Regions}

The models that best capture the dependence structure between London and other regions, and the difference in conditional probabilities with the benchmark models, are provided in Table 7. Except for $\mathrm{YH}$, all other regions are characterised by time-varying dependence based on SIC value comparisons. Thus, by and large, our results are in line with those of Zimmer (2015) which show that time-variation is an important feature in modelling the dependence structure between regional house prices. A Student's $t$ copula, which has symmetric tail dependence, is found to adequately describe the dependence structure between $\mathrm{YH}$ and London. The dependence structures between London and N, SC and WA are best described by the time-varying rotated Gumbel copula, indicating left tail dependence. This implies that house prices in N, SC and WA are more likely to experience a joint crash with London prices. For EA, we find evidence of right tail dependence as indicated by the fit of the time-varying Gumbel copula which implies that London and EA prices are more likely to boom, rather than crash, together. The remaining regions (NW, EM, WM, OSE, OM, SW, NI) do not display tail dependence with London, but they exhibit a time-varying relationship that is best described by a Normal copula.

In terms of the difference in conditional probabilities, a number of the observations made in the preceding discussions also hold here. As shown in Table 7 using the wrong model can lead to a severe overestimation or underestimation of the probability of joint crashes or booms. The comparison of conditional probabilities also reveals that there are widespread differences in the dependence between London and other regions. For example, if one incorrectly uses the constant Normal copula, the crash risk would be substantially underestimated for N, SC and WA (by $17.7 \%, 17.8 \%$ and $19.2 \%$ on average, respectively) but significantly overestimated for EA (by $6.6 \%$ on average). These results also reinforce the earlier finding that significant regional differences exist in the behaviour of the housing market. While earlier studies have primarily used linear models to 


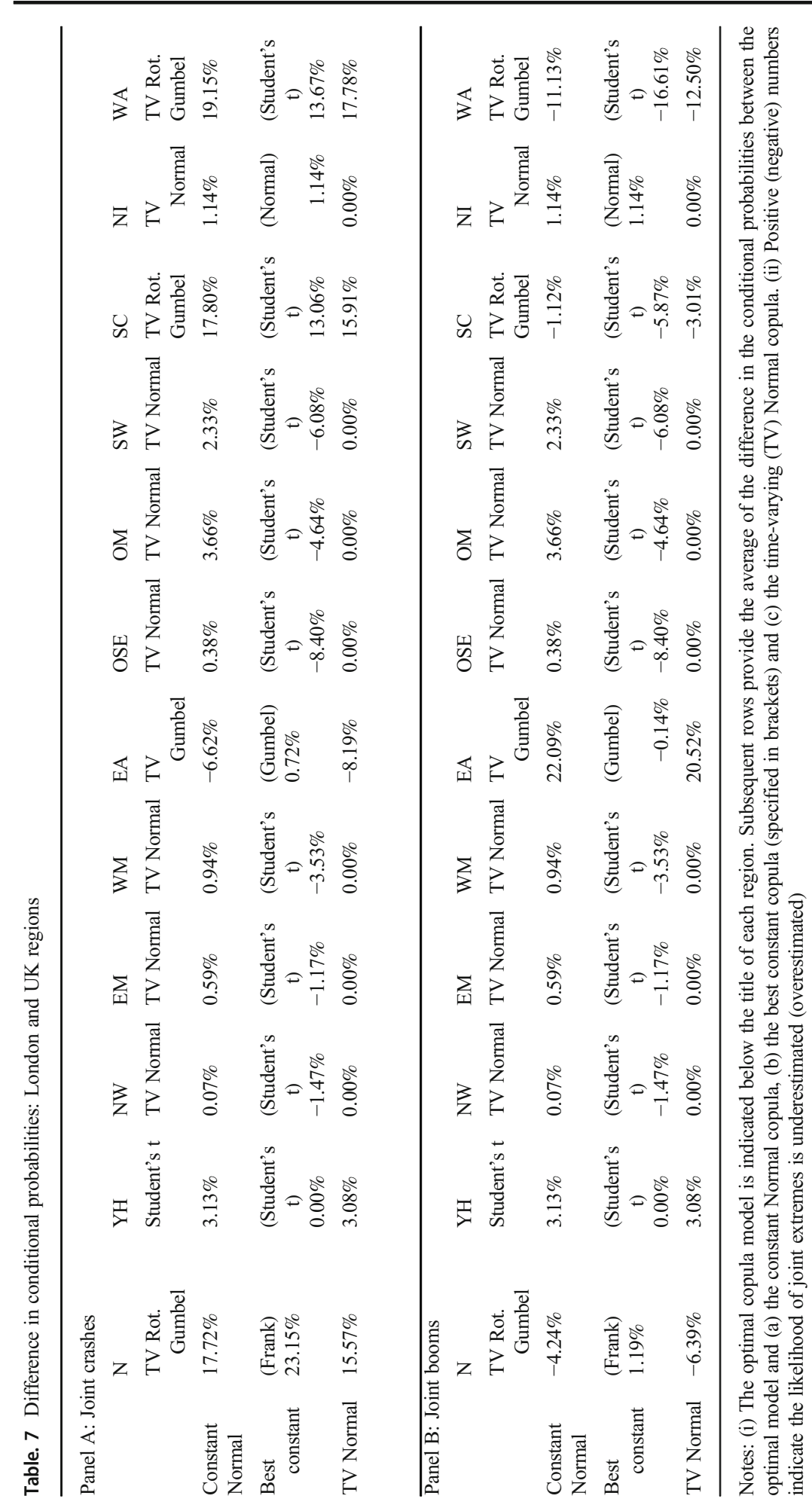


study the linkages between property prices in London and other parts of the UK, our analysis shows that these linkages are predominantly time-varying and the nature of dependence varies greatly from region to region.

\section{Concluding Remarks}

In this paper, we attempt to gain further insights into the relationship between the UK housing and stock markets. In particular, we employ copula functions which allow us to examine nonlinear associations between the two markets, including increased dependence in the tails. Our empirical analysis is conducted at both the national and regional levels. We also investigate how closely house prices in different parts of the UK are linked to those in London given that earlier studies have suggested that the latter tend to influence UK regional prices.

Previous UK studies have shown that the housing and stock markets share a positive relationship at the national level and may exhibit left tail dependence. We also find evidence supporting these results. Further to these, our findings suggest that the stock and housing markets exhibit left tail dependence which is time-varying. The left tail dependence signifies that the two markets are more likely to crash together. Therefore, any severe instability in one market is likely to coincide with turmoil in the other. We also show that using the wrong model can lead to a severe underestimation or overestimation of the likelihood of joint crashes or booms. These findings have important implications for investors, financial institutions, and policymakers alike. Our results suggest that the increased contagion in down markets will erode diversification benefits when they are needed the most since during periods of economic turmoil neither the stock nor the housing market will provide refuge. For institutions and investors that have significant exposures to both the stock and real estate markets, our study highlights the challenges of remaining financially sound during the downturns of the economic cycle and the danger of under-predicting risk if nonlinear dependence is ignored.

Our analysis at the regional level provides further insights into the relationship between house prices and the stock market in the UK. Only five of the 13 regions share a similar dependence structure to the national level. These findings suggest that any national-level policy aimed at influencing the housing market in the UK will not necessarily have the desired effect across all regions. The dependence structure between property prices in London and other parts of the UK also show widespread regional differences. Similar to the findings at the national level, time-variation is a salient feature of the dependence structure at the regional level.

Overall, our results are of direct relevance to policymakers in the UK and worldwide. Specifically, as our study clearly demonstrates, the stock and housing markets have complex and intricate links with each other that must be taken into account before any regulatory or fiscal intervention is designed. Ignoring these, even well-intended policies can result in destabilising results.

Acknowledgments We would like to thank the anonymous referees whose comments have helped us improve the paper. 
Open Access This article is licensed under a Creative Commons Attribution 4.0 International License, which permits use, sharing, adaptation, distribution and reproduction in any medium or format, as long as you give appropriate credit to the original author(s) and the source, provide a link to the Creative Commons licence, and indicate if changes were made. The images or other third party material in this article are included in the article's Creative Commons licence, unless indicated otherwise in a credit line to the material. If material is not included in the article's Creative Commons licence and your intended use is not permitted by statutory regulation or exceeds the permitted use, you will need to obtain permission directly from the copyright holder. To view a copy of this licence, visit http://creativecommons.org/licenses/by/4.0/.

\section{References}

Aye, G., Balcilar, M., \& Gupta, R. (2013). Long-and short-run relationships between house and stock prices in South Africa: A nonparametric approach. Journal of Housing Research, 22, 203-219.

Berkowitz, J. (2001). Testing density forecasts with applications to risk management. Journal of Business and Economic Statistics, 19, 465-474.

Bissoondeeal, R.K. (2021). The links between regional house prices and share prices in the UK. Regional Studies, 55, 256-268.

Bollerslev, T. (1987). A conditionally heteroskedastic time series model for speculative prices and rates of return. The Review of Economics and Statistics, 69, 542-547.

Creal, D. D., Koopman, S. J., \& Lucas, A. (2013). Generalized autoregressive score models with applications. Journal of Applied Econometrics, 28, 777-795.

Diebold, F. X., Gunther, T. G., \& Tsay, A. S. (1998). Evaluating density forecasts, with applications to financial risk management. International Economic Review, 39, 863-883.

Ding, H., Ching, T. T., \& Park, S. Y. (2014). Nonlinear dependence between stock and real estate markets in China. Economics Letters, 124, 526-529.

Eichholtz, P., \& Hartzell, D. (1996). Property shares, appraisals and the stock market: An international perspective. Journal of Real Estate Finance and Economics, 12, 163-178.

Glosten, L. R., Jagannathan, R., \& Runkle, D. E. (1993). On the relation between the expected value and the volatility of the nominal excess return on stocks. The Journal of Finance, 48, 1779-1801.

Green, R. K. (2002). Stock prices and house prices in California: New evidence of a wealth effect? Regional Science and Urban Economics, 32, 775-783.

Hansen, B. E. (1994). Autoregressive conditional density estimation. International Economic Review, 35, $705-730$.

Ho, A. T. Y., Kim, P. H., \& David, T. J. C. (2016). Flexible estimation of copulas: An application to the US housing crisis. Journal of Applied Econometrics, 31, 603-610.

Holly, S., Pesaran, M. H., \& Yamagata, T. (2011). The spatial and temporal diffusion of house prices in the UK. Journal of Urban Economics, 69, 2-23.

Kakes, J., \& Van Den End, J. W. (2004). Do stock prices affect house prices? Evidence from the Netherlands. Applied Economics Letters, 11, 741-744.

Kapopoulos, P., \& Siokis, F. (2005). Stock and real estate prices in Greece: Wealth versus 'credit-price' effect. Applied Economics Letters, 12, 125-128.

Knight, J., Lizieri, C., \& Satchell, S. (2005). Diversification when it hurts? The joint distributions of real estate and equity markets. Journal of Property Research, 22, 309-323.

Lean, H. H., \& Smyth, R. (2014). Dynamic interaction between house prices and stock prices in Malaysia. International Journal of Strategic Property Management, 18, 163-177.

MacDonald, R., \& Taylor, M. P. (1993). Regional house prices in Britain: Long-run relationships and shortrun dynamics. Scottish Journal of Political Economy, 40, 43-55.

Ning, C. (2010). Dependence structure between the equity market and the foreign exchange market - A copula approach. Journal of International Money and Finance, 29, 743-759.

Okunev, J., Wilson, P., \& Zurbruegg, R. (2000). The causal relationship between real estate and stock markets. Journal of Real Estate Finance and Economics, 21, 251-261.

Patton, A. J. (2006). Modelling asymmetric exchange rate dependence. International Economic Review, 47, 527-556.

Patton, A. J. (2013). Copula methods for forecasting multivariate time Ssries. In Handbook of economic forecasting, volume 2. Verlag: Springer. 
Sklar, A. (1959). Fonctions de répartition à n dimensions et leurs marges. Paris Publications de l'Institut de Statistique de l'Université de Paris, 8, 229-231.

Sutton, G. D. (2002). Explaining changes in house prices. BIS Quarterly Review (September), 46-55.

Zimmer, D. M. (2012). The role of copulas in the housing crisis. Review of Economics and Statistics, 94, 607620.

Zimmer, D. M. (2015). Time-varying correlation in housing prices. The Journal of Real Estate Finance and Economics, 51, 86-100.

Publisher's Note Springer Nature remains neutral with regard to jurisdictional claims in published maps and institutional affiliations. 